\title{
Hypothermia Suppresses Uncoupling of Oxidative- Phosphorylation after Neonatal Cerebral Hypoxia-Ischemia
}

Naidi Sun ${ }^{1,2,8}$, Yu-Yo Sun ${ }^{3,4,8}$, Rui $\mathrm{Cao}^{2}$, Hong-Ru Chen ${ }^{4}$, Yiming Wang ${ }^{2}$, Elizabeth Fugate ${ }^{5}$, Marchelle R. Smucker ${ }^{4}$, Yi-Min Kuo ${ }^{6}$, P. Ellen Grant ${ }^{7}$, Diana M. Lindquist ${ }^{5}$, Chia-Yi Kuan ${ }^{4,9}$, Song $\mathrm{Hu}^{1,9}$

1: Washington University, Department of Biomedical Engineering

2: University of Virginia, Department of Biomedical Engineering

3: National Sun Yat-sen University, Kaohsiung, Taiwan

4: University of Virginia, Department of Neuroscience; Center for Brain Immunology and Glia (BIG)

5: Cincinnati Children's Hospital Medical Center, Imaging Research Center, Department of Radiology

6: Taipei Veterans General Hospital. Department of Anesthesiology

7: Boston Children's Hospital, Fetal-Neonatal Neuroimaging \& Developmental Science Center

8. Equal-contribution authors

9: Co-responding senior authors

\section{Correspondence:}

SongHu (songhu@wustl.edu)

Department of Biomedical Engineering, Washington University

Brauer Hall, Room 2009, Washington University in St. Louis, St. Louis, MO 63130, USA

or

Chia-Yi Kuan (alex.kuan@virginia.edu)

Department of Neuroscience, University of Virginia School of Medicine, 409 Lane Road, MR-4, 4046, Charlottesville, VA 22908, USA

Conflicts of interest: The authors declare no conflict of interest. 
Hypothermia is the best available therapy for neonatal hypoxia-ischemia (HI) brain injury, but its primary mechanisms remain uncertain 1 . We hypothesize that HI induces, whereas hypothermia represses, uncoupling of oxidative-phosphorylation (OXPHOS) — an increase of the cerebral metabolic rate of oxygen $\left(\mathrm{CMRO}_{2}\right)$ despite reduction of the mitochondrial energy output ${ }^{2,3}$. We used a multi-parametric photoacoustic microscopy (PAM) system to compare the effects of $\mathrm{HI}$ and post-HI hypothermic treatment on $\mathrm{CMRO}_{2}$ in awake 10-dayold (P10) mice ${ }^{4-9}$. Here we show that hypoxia $\left(10 \% \mathrm{O}_{2}\right)$ elevated $\mathrm{CMRO}_{2}$, but the addition of unilateral carotid artery ligation suppressed $\mathrm{CMRO}_{2}$ and sparked a rapid overshoot of post-HI CMRO $\mathrm{CM}_{2}$ in the ipsilateral cerebral cortex for at least 2 hours. The post-HI surge of $\mathrm{CMRO}_{2}$ was linked to an increase of mitochondrial oxygen consumption and superoxide outburst, despite reduction of the mitochondrial membrane potential. Notably, post-HI hypothermia blocked the surge of superoxide and $\mathrm{CMRO}_{2}$ - primarily by limiting oxygen extraction fraction (OEF) - leading to better preservation of adenosine triphosphate (ATP), creatine (Cr) and N-acetylaspartate (NAA) after HI. Mice that did not receive hypothermia exhibited $\sim 80 \%$ reduction of $\mathrm{CMRO}_{2}$ at $24 \mathrm{~h}$ post-HI, coupled to a large cortical infarction. These results suggest that mitigation of post-HI uncoupling of OXPHOS is an early and/or pivotal effect of hypothermia. Further, optical measurement of $\mathrm{CMRO}_{2}$ may be a sensitive and non-invasive method to monitor brain damage in hypoxic-ischemic encephalopathy (HIE) ${ }^{10-15}$. (224 words)

The human brain constitutes only $2 \%$ of the body mass, but accounts for around $20 \%$ of body's oxygen consumption to maintain neuronal viability and activities ${ }^{16,17}$. Brain oxygen metabolism, as measured by $\mathrm{CMRO}_{2}$, remains stable over a wide range of cerebral blood flow (CBF) due to compensatory changes of OEF in the opposite direction ${ }^{3,17,18}$. In adult cerebral ischemia, $\mathrm{CMRO}_{2}$ in the penumbra area is sustained at $44-66 \%$ of normal values, whereas $>60 \%$ reduction of $\mathrm{CMRO}_{2}$ signifies looming infarction ${ }^{19}$. Hence, measuring the regional $\mathrm{CMRO}_{2}-$ originally using radiotracers, but now often with magnetic resonance imaging (MRI) methodspredicts brain damage in adult stroke ${ }^{17,20}$. However, $\mathrm{MRI}$-based $\mathrm{CMRO}_{2}$ measurement remains a difficult procedure in infants ${ }^{21}$. In contrast, the combination of diffuse correlation spectroscopy (DCS) and frequency-domain near-infrared spectroscopy (FDNIRS) or time-resolved nearinfrared spectroscopy (TRNIRS) provides absolute $\mathrm{CMRO}_{2 \mathrm{i}}$ measurements through the intact 
infant skull ${ }^{11-15}$. It has been shown that FDNIRS/DCS-defined $\mathrm{CMRO}_{2 \mathrm{i}}$ correlates tightly with MRI-based $\mathrm{CMRO}_{2}$ values and declines during therapeutic hypothermia ${ }^{12-14}$. Notably, one of us (P.E.G.) previously found higher $\mathrm{CMRO}_{2 \mathrm{i}}$ in infants with $\mathrm{HIE}$ symptoms, in contrast to a report of reduced $\mathrm{CMRO}_{2}$ during early recovery of $\mathrm{HI}$ in piglets ${ }^{22-23}$. The discrepancy may be caused by anesthesia used in the preclinical study, which is known to reduce brain functions and metabolic activities $^{24-25}$. Thus, we adapted a head-restrained, multi-parametric PAM system ${ }^{9}$ to compare the effects of $\mathrm{HI}$ with and without post-HI hypothermic treatment on $\mathrm{CMRO}_{2}$ in awake $\mathrm{P} 10$ mice.

Our PAM system used two nanosecond-pulsed lasers (wavelengths: 532 and $558 \mathrm{~nm}$ ) to derive simultaneous high-resolution imaging of $\mathrm{CBF}$, blood hemoglobin concentration $\left(\mathrm{C}_{\mathrm{Hb}}\right)$, and oxygen saturation $\left(\mathrm{sO}_{2}\right)$, which were used to calculate regional $\mathrm{CMRO}_{2}$ (Fig. 1a and see Methods for details about the PAM system $)^{6-9}$. An awake P10 mouse was placed between the head plate and a plastic ball for imaging, and hypothermia was achieved by adjusting the temperature of the water tank above the mouse head (Fig. 1b; Supplementary Fig 1). A $5 \times 3 \mathrm{~mm}^{2}$ area covering between the Bregma and Lambda in both hemispheres was scanned through the exposed, but intact mouse skull in 40 min by the PAM system (Fig. 1c). Using this system, we first examined the effects of hypothermia on cerebral oxygen metabolism. We found that $\mathrm{CMRO}_{2}$ fell to $86 \%$ of $37{ }^{\circ} \mathrm{C}$ values at $32{ }^{0} \mathrm{C}$ and plunged to $50 \%$ at $29{ }^{\circ} \mathrm{C}$, with greater effects of hypothermia on $\mathrm{CBF}$ (reduction to $86 \%$ at $32{ }^{\circ} \mathrm{C}$ and to $59 \%$ at $29{ }^{\circ} \mathrm{C}$ ) than $\mathrm{OEF}$ (decline to $89 \%$ at $32{ }^{\circ} \mathrm{C}$ and to $85 \%$ at $29{ }^{\circ} \mathrm{C}$ ) (Fig. 1d, e; $\mathrm{n}=4$ for each). We also examined the effects of hypoxia $\left(10 \% \mathrm{FiO}_{2}\right)$, first in anesthetized P10 mice, and detected a rise of $\mathrm{CMRO}_{2}$ (Fig. 1f, g; $\mathrm{n}=6$ ). Though counter-intuitive (i.e. sparse oxygen stimulates oxygen consumption), our finding of hypoxia-induced $\mathrm{CMRO}_{2}$ in $10 \% \mathrm{FiO}_{2}$ are in accord with the reports by $\mathrm{MRI}-\mathrm{CMRO}_{2}$ methods and increased cytochrome $\mathrm{c}$ oxidase $(\mathrm{CCO})$ activity under moderate hypoxia $\left(>8 \% \mathrm{FiO}_{2}\right)^{26,27}$.

Next, we examined the changes of $\mathrm{CMRO}_{2}$ during and immediately after the Vannucci model of $\mathrm{HI}$ in awake P10 mice ${ }^{28,29}$. We found that the $\mathrm{CMRO}_{2}$ between two hemispheres were comparable after the unilateral common carotid artery (CCA) ligation, because the CCA-ligated hemisphere showed a higher OEF to compensate for the diminished CBF (Fig. 2a, b; n=5). When hypoxia was superimposed, the contralateral hemisphere showed an elevation of $\mathrm{CMRO}_{2}$, while $\mathrm{CMRO}_{2}$ in the CCA-ligated hemisphere declined due to the reduction of OEF and small increase of $\mathrm{CBF}$. Immediately after hypoxia, the $\mathrm{CMRO}_{2}$ in contralateral hemisphere returned to the pre- 
hypoxia level and rose slowly over time (Fig. 2c). In contrast, the ipsilateral hemisphere showed a surge of $\mathrm{CMRO}_{2}$ that was higher than the pre-hypoxia level for at least two hours (Fig. 2b,c).

To explore the causes of post-HI overshoot of $\mathrm{CMRO}_{2}$, we first monitored the mice using electroencephalography (EEG) $)^{30}$. Video-EEG in the post-HI period showed a gradual recovery of suppression without seizure-like behaviors (Fig $2 \mathrm{~d}$; $\mathrm{n}=6$ ), suggesting that status epilepticus is not the cause for post-HI surge of $\mathrm{CMRO}_{2}{ }^{3}$. We then isolated the cortical mitochondria at 2 or $5 \mathrm{~h}$ post-HI and from the unchallenged (UN) mouse brains for in-vitro analysis ${ }^{31}$. The mitochondria from the ipsilateral cortex at $2 \mathrm{~h}$ post-HI showed a higher oxygen consumption rate (OCR) and greater MitoSox fluorescence emission (an indicator of superoxide), despite reduction of the mitochondrial membrane potential ( $\psi_{\mathrm{m}}$ : it drives ATP production through $\mathrm{F}_{1} \mathrm{~F}_{0}$ ATPase and is measured by $\Delta \mathrm{RH}-123$ fluorescence $)^{2,3}$, compared with those in the contralateral cortex and UN mouse brains (Fig. 2e-h; $\mathrm{n}=7$ each). At $5 \mathrm{~h}$ post-HI, the mitochondria from ipsilateral cortex still emitted more superoxide, but exhibited reduction of both OCR and $\psi_{\mathrm{m}}$ (Fig. 2e-h). The observed pattern is similar to the findings of greater oxygen consumption and free radical emission despite reduction of $\psi_{\mathrm{m}}$ in cardiomyocytes after hypoxia ${ }^{32-35}$. Together, our results suggested uncoupling of OXPHOS and rapid mitochondrial injury after neonatal cerebral HI.

Next, we assessed the effects of post-HI hypothermia on $\mathrm{CMRO}_{2}$, with the mouse skull temperature reduced to $32^{\circ} \mathrm{C}$ after hypoxia in continuous PAM scan. As expected, the effects of CCA-ligation and combined $\mathrm{HI}$ in this experiment were essentially the same as those described in Figure 2, with $\mathrm{CMRO}_{2}$ reduced during $\mathrm{HI}$ in the ipsilateral hemisphere in contrast to $\mathrm{CMRO}_{2}$ elevation in contralateral hemisphere (Fig. 3a-c; n=5). However, post-HI hypothermia repressed $\mathrm{CMRO}_{2}$ in both hemispheres to nearly the pre-HI level for at least two hours (Fig. 3b, c). The PAM results suggested that the chief effect of post-HI hypothermic treatment was to prevent the rise of OEF in the ipsilateral hemisphere, rather than reduction of CBF as in uninjured mice (Fig. 3d-f). We then compared the mitochondria isolated from HI-injured mice, either with or without $4 \mathrm{~h}$ hypothermia, at $5 \mathrm{~h}$ post-HI. The mitochondria in the HI-injured mice without hypothermic treatment showed significant reduction of OCR, hydrogen peroxide $\left(\mathrm{H}_{2} \mathrm{O}_{2}\right)$ and $\psi_{\mathrm{m}}$, but increased superoxide, compared with the contralateral hemisphere (Fig. 3h-j). In contrast, the mitochondria isolated from hypothermia-treated mice showed marked improvement of OCR, $\mathrm{H}_{2} \mathrm{O}_{2}, \psi_{\mathrm{m}}$, and reduction of superoxide to nearly the contralateral hemisphere values (Fig. 3g-j). By 6 h post-HI, the ipsilateral forebrain of hypothermia-treated mice contained a higher level of ATP, compared 
with the mice that recovered in normothermia (Fig. 4a; $n=3$ ). By $24 \mathrm{~h}$ post-HI, the mice that recovered under normothermia showed significant reduction of total creatine $(\mathrm{Cr} / \mathrm{PCr})$, choline (Cho), glutamate and glutamine (Glx) and N-acetyl aspartate (NAA) in ipsilateral forebrains by proton nuclear magnetic resonance analysis (Fig. $4 b, n=5)^{36}$. In contrast, the mice that received hypothermia treatment only showed significant reduction of Glx in ipsilateral forebrains (Fig. 4c, n=3; Supplementary Fig 2). Together, these results confirmed protective benefits by hypothermia in neonatal HI brain injury ${ }^{37}$.

Finally, we tested whether the PAM-based $\mathrm{CMRO}_{2}$ detects post-HI brain damage, similar to $\mathrm{MRI}-\mathrm{CMRO}_{2}$ for predicting infarction in adult ischemic stroke ${ }^{17,19}$. In average, PAM detected a significant decline of $\mathrm{CBF}, \mathrm{OEF}$, and $\mathrm{CMRO}_{2}$ in the ipsilateral hemisphere at $24 \mathrm{~h}$ in mice that did not receive the hypothermia treatment (Fig. 4d-f; $n=4$ ). In contrast, mice that were treated by hypothermia maintained similar $\mathrm{CBF}, \mathrm{OEF}$, and $\mathrm{CMRO}_{2}$ between hemispheres (Fig 4d-f; $\mathrm{n}=4$ ). Further, a mouse that recovered in normothermia and showed $23.7 \%$ of the contralateral $\mathrm{CMRO}_{2}$ value also manifested impaired triphenyltetrazolium chloride (TTC) stain, in contrast to normal TTC stain and better retention of $\mathrm{CMRO}_{2}(85.3 \%$ of the contralateral value $)$ at $24 \mathrm{~h}$ recovery in a mouse that received post-HI hypothermia treatment (Fig. 4g, h). Finally, mice that received postHI hypothermia showed a significant reduction of brain infarct at $24 \mathrm{~h}$, when compared to those recovered in normothermia (Fig. 4i; $\mathrm{n}=10$ and 6 as indicated).

\section{Discussion:}

Metabolic brain measurements using optical methods have a great potential in the clinical care of infants ${ }^{10,38}$. In particular, optical $\mathrm{CMRO}_{2 \mathrm{i}}$ measurements may detect irreversible brain damage in neonates suffered from birth asphyxia, similar to $\mathrm{MRI}-\mathrm{CMRO}_{2}$ in adult ischemic stroke ${ }^{17,19}$, but clinical application of optical $\mathrm{CMRO}_{2 \mathrm{i}}$ is still in development ${ }^{11-15}$. In this study, we used PAM to investigate how HI affects brain oxygen metabolism and interacts with therapeutic hypothermia in murine neonates, and correlated them with mitochondrial respiration and brain energetics ${ }^{39,40}$. We found that the combination of hypoxia with unilateral carotid artery ligation has contrasting effects on oxygen metabolism between the two cerebral hemispheres. In contralateral cortex, the $\mathrm{CMRO}_{2}$ rises during $\mathrm{HI}$ and returns close to the pre-hypoxia level after hypoxia, correlated with a modest increase of lactate and small reduction of PCr and ATP, as shown in a past study (Fig. $4 \mathrm{j})^{41}$. In contrast, the $\mathrm{CMRO}_{2}$ in the ipsilateral hemisphere markedly declined during $\mathrm{HI}$, which 
may cause more severe reduction of brain energetics and lactate accumulation $(\text { Fig. } 4 \mathrm{j})^{41}$. This complex oxygen debt plus acidosis may incite the surge of OEF and mitochondrial respiration acutely after hypoxia, as shown in our results ${ }^{42,43}$. Persistent elevation of $\mathrm{CMRO}_{2}$ also occurs after cortical spreading depression ${ }^{44}$, but to a lesser level than what we have found after neonatal HI. Importantly, rapid resumption of mitochondrial respiration after HI may be harmful to cells, because the mitochondrial electron-transfer chain (ETC) is in an uncoupled OXPHOS state and prone to reactive oxygen species (ROS) emission ${ }^{35}$. The factors that contribute to the uncoupling of OXPHOS may include reverse electron transport through Complex I, calcium overload in the matrix, nitric oxide-mediated suppression of CCO, and ROS-induced destabilization of the ETC

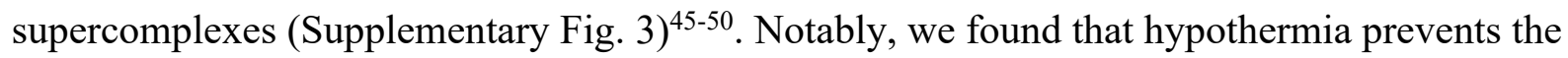
surge in $\mathrm{OEF}$, rather than reduction of $\mathrm{CBF}$ as in uninjured mice, to suppress the post-HI surge of $\mathrm{CMRO}_{2}$. The lack of marked effects on CBF by post-HI hypothermia in our results is similar to a previous report ${ }^{51}$ and suggests that hypothermia directly inhibits the drive for mitochondrial respiration after HI. It is known that hypothermia represses glycolysis, lactate accumulation, and cerebral uptake of blood glucose ${ }^{52-54}$, which may jointly disrupt the vicious cycles of OXPHOS uncoupling and ROS outburst in the HI-injured neonatal brains (Fig. 4j).

In conclusion, our results suggest that suppression of uncoupled OXPHOS may be an early and/or critical mechanism of therapeutic hypothermia. Further, measurement of $\mathrm{CMRO}_{2}$ by optical methods may a sensitive means to detect brain damage and titrate hypothermia treatment in neonatal HIE. 


\section{Figure Legends:}

\section{Figure 1. Effects of hypothermia and pure-hypoxia on cerebral oxygen metabolism in}

awake mouse neonates. a, Schematic of the head-restrained multi-parametric photoacoustic microscopy (PAM) system. PA: photoacoustic; PD: photodiode; HWP: half-wave plate; PBS: polarizing beam splitter; NDF: neutral-density filter; PM-SMF: polarization-maintaining singlemode fiber; BPF: band-pass filter; DBS: dichroic beam splitter; BS: beam sampler; SMF: singlemode fiber; DL: doublet; CL: correction lens; UT: ring-shaped ultrasonic transducer; WT: water tank; PB: plastic ball. b, Photo of an awake 10-day-old mouse in the PAM system. Note that the water tank is removed to show the mouse and the head plate in the photo. c, Illustration of the imaging field $\left(5 \times 3 \mathrm{~mm}^{2}\right)$ that covers both hemispheres between the Bregma and Lambda on the skull of P10 mice. d, Projection of the z-stack images of hemoglobin oxygenation (sO2) and blood flow speed in an awake P10 mouse whose skull temperature was upheld at 37, to 32, and to $29{ }^{\circ} \mathrm{C}$. The superior sagittal sinus separating the two cerebral hemispheres were in in the midline of image. e, The calculated CBF (ml/100g/min), OEF, and $\mathrm{CMRO}_{2}(\mathrm{ml} / 100 \mathrm{~g} / \mathrm{min})$ values at these three skull temperatures. Shown are mean $\pm \mathrm{SD} ; \mathrm{n}=4$; $\mathrm{p}$-values were determined by one-way ANOVA. f, PAM images of $\mathrm{sO}_{2}$ and $\mathrm{CBF}$ speed in anesthetized P10 mouse (with $1 \%$ isoflurane) under normoxia versus hypoxia (10\% oxygen). $\mathbf{g}$, The changes of CBF, OEF, and $\mathrm{CMRO}_{2}$ in normoxia-versus-hypoxia. Shown are mean $\pm \mathrm{SD} ; \mathrm{n}=5 ; \mathrm{p}$-values were determined by one-way ANOVA.

\section{Figure 2: Effects of hypoxia/ischemia on $\mathrm{CMRO}_{2}$ and mitochondrial respiration under}

normothermia. a, Sequential $\mathrm{sO}_{2}$ and $\mathrm{CBF}$ images of an awake $\mathrm{P} 10$ mouse under unilateral CCA-ligation, combined hypoxia-ischemia (HI), and at 0-40, 40-80, plus 80-120 min post-HI under normothermia. The superior sagittal sinus in the midline of image separates the CCAligated (ipsilateral) and contralateral hemispheres. b, c, Tabulation and tracing of the CBF, OEF, and $\mathrm{CMRO}_{2}$ changes in contralateral and ipsilateral hemispheres in the indicated period. Shown are mean $\pm \mathrm{SD} ; \mathrm{n}=5 ; *: \mathrm{p}<0.05 ; * *: \mathrm{p}<0.01$ compared to the "CCA-ligation" in its own hemisphere, unless indicated otherwise (with the bracket). The p-values were determined by twoway ANOVA. d, EEG recording of the ipsilateral cortex in a P10 mouse with right CCA-ligated in the ambient environment, hypoxia ( $10 \%$ oxygen for $60 \mathrm{~min})$, and for $1 \mathrm{~h}$ post-hypoxia $(\mathrm{n}=6)$. Characteristic EEG patterns (1-4) in individual periods were highlighted. 1: pre-HI baseline; 2: 
suppression; 3: burst-suppression correlated with seizure behaviors on video-EEG (denoted by asterisks); 4: post-hypoxia suppression. e, f, Oxygen consumption of the mitochondria isolated from unchallenged (UN), ipsilateral, contralateral cortex at 2 or $5 \mathrm{~h}$ post-HI. The state-3 oxygen consumption rate (OCR) in the ipsilateral cortex was significantly increased at $2 \mathrm{~h}$, but reduced at $5 \mathrm{~h}$ post-HI. $\mathbf{g}, \mathbf{h}$, Comparison of the MitoSox Red (indicator of mitochondrial superoxide) and $\Delta \mathrm{RH}-123$ (the measurement of $\psi_{\mathrm{m}}$ ) fluorescence units (AU). Shown are mean $\pm \mathrm{SD} ; \mathrm{n}=7$ for each group; the p-values were determined by one-way ANOVA; NS: $p>0.05$.

\section{Figure 3: Effects of post-HI hypothermia on $\mathrm{CMRO}_{2}$ and the mitochondrial integrity.}

a, Sequential $\mathrm{sO}_{2}$ and $\mathrm{CBF}$ images of an awake $\mathrm{P} 10$ mouse under unilateral CCA-ligation, combined hypoxia-ischemia (HI), and at 0-40, 40-80, plus 80-120 min post-HI. The hypothermia treatment was started immediately after hypoxia by adjusting the temperature of water tank in the PAM system to keep the mouse skull temperature at $32{ }^{\circ} \mathrm{C}$. b, c, Tabulation and tracing of the $\mathrm{CBF}, \mathrm{OEF}$, and $\mathrm{CMRO}_{2}$ changes in contralateral and ipsilateral hemispheres in the indicated period. Shown are mean $\pm \mathrm{SD} ; \mathrm{n}=5 ; *: \mathrm{p}<0.05 ; * *: \mathrm{p}<0.01$ compared to the "CCA-ligation" in its own hemisphere, unless indicated otherwise (with the bracket; ***: $\mathrm{p}<0.001 ; * * * *: \mathrm{p}<0.0001$ ). p-values were determined by two-way ANOVA. d-f, Comparison of the ipsilateral CBF, OEF, and $\mathrm{CMRO}_{2}$ values in the mice that were imaged before and during $\mathrm{HI}$, followed by recovery under normothermia versus hypothermia. $\mathrm{n}=5$; Shown are mean $\pm \mathrm{SD} ; *$ : $\mathrm{p}<0.05$ by two-way ANOVA. Note that hypothermia decreases post-HI $\mathrm{CMRO}_{2}$ primarily through suppression of OEF, but not CBF in this condition. g-j, Comparison of OCR, MitoSox Red fluorescence, $\mathrm{H}_{2} \mathrm{O}_{2}$ emission rate, and $\Delta \mathrm{RH}-123$ fluorescence in the mitochondrial isolated from contralateral and ipsilateral cortex in HI-injured mice that received normothermia-versus-hypothermia treatment for $4 \mathrm{~h}$, followed by another hour in normothermia. $\mathrm{n}=5$; Shown are mean $\pm \mathrm{SD}$; $\mathrm{p}$-values determined by two-way ANOVA.

\section{Figure 4: Correlation of $\mathrm{CMRO}_{2}$ and post-HI brain damage in mouse neonates.}

a, Comparison of the mouse forebrain ATP concentrations at $6 \mathrm{~h}$ post-HI (including $4 \mathrm{~h}$ or 37 versus- $32{ }^{\circ} \mathrm{C}$ treatment). Shown are mean $\pm \mathrm{SEM} ; *$ : $\mathrm{p}<0.05$ by two-way ANOVA and Tukey's post-hoc test. Note that hypothermia treatment led to better preservation of the brain ATP levels. b, c, Characteristic proton-HRMAS spectrum of the snap-frozen ipsilateral and contralateral 
forebrain in HI-injured mice at $24 \mathrm{~h}$ post-HI (including normothermia-versus-hypothermia treatment for $4 \mathrm{~h}$ ). The spectrums are scaled to the same peak height for myo-inositol. $\mathrm{Cr}$ : creatine and phosphocreatine; Cho: choline, Glx: glutamate and glutamine; NAA: N-acetyl aspartate. $\mathrm{n}=5$ for normothermia and $\mathrm{n}=3$ for hypothermia. $*: \mathrm{p}<0.05 ; * * \mathrm{p}<0.01$ compared to the contralateral side in group analysis using two-way ANOVA. d-f, Comparison of CBF, OEF, and $\mathrm{CMRO}_{2}$ values at $24 \mathrm{~h}$ post-HI, including normothermia-versus-hypothermia treatment for 4 h. CL: contralateral side; HI: ipsilateral side. $\mathrm{n}=4$ for each; Shown are mean $\pm \mathrm{SD}$; $\mathrm{p}$-values were determined by two-way ANOVA. g, Representative $\mathrm{sO}_{2}$ and $\mathrm{CBF}$ images of mice at $24 \mathrm{~h}$ post-HI (including normothermia-versus-hypothermia treatment for $4 \mathbf{h}$ ). $\mathbf{h}$, The $\mathrm{CMRO}_{2}$ map and values of one pair of representative mice whose brains were immediately removed after PAM imaging and dipped into the TTC dye to detect infarction. Note the normothermia-treated mouse showed severe reduction of $\mathrm{CMRO}_{2}$ in the ipsilateral hemisphere $(23.7 \%$ of the contralateral) correlated with large infarction. In contrast, hypothermia-treated mice maintained the ipsilateral $\mathrm{CMRO}_{2}$ at $85 \%$ of contralateral side and showed no sign for infarction. $\mathbf{i}$, Comparison of the infarct volume in HI-injured mice with $(n=6)$ or without the hypothermia treatment $(n=10)$. Shown are mean \pm $\mathrm{SD}$; p-values were determined by unpaired $t$-test. j. Schematic conclusion and the hypothesis based our results and previous reports. The combined HI in Vannucci model produced complex "oxygen debt" (severe lactate accumulation plus depletion of ATP and PCr) ${ }^{41}$ after hypoxia and triggered a vicious cycle of enhanced glycolysis/acidosis, uncoupled OXPHOS, ROS production and mitochondrial damage. Hypothermia has direct inhibitory effects on glycolysis and the TCA cycle that fuels OXPHOS ${ }^{52-54}$.

Supplementary Figure 1: Relationship of the water tank and mouse skull temperatures.

Supplementary Figure 2: ${ }^{1} \mathrm{H}$ HRMAS MRS analysis of the effects of hypothermia on brain metabolites at $24 \mathrm{~h}$ post-HI.

Supplementary Figure 3: Potential mechanisms that contribute to uncoupling of OXPHOS after HI and the effects of therapeutic hypothermia. 


\section{References:}

1. Gunn AJ, Laptook AR, Robertson NJ, Barks JD, Thoresen M, Wassink G, Bennet L (2017) Therapeutic hypothermia translates from ancient history in to practice. Pediatr Res 81:202209.

2. Kramer RS, Pearlstein RD (1983) Reversible uncoupling of oxidative phosphorylation at low oxygen tension. Proc Natl Acad Sci U S A 80:5807-5811.

3. Siesjo BK (1978) Brain Energy Metabolism, Chichester, England, Wiley.

4. Wang LV, Hu S (2012) Photoacoustic tomography: in vivo imaging from organelles to organs. Science 335:1458-1462.

5. Hu S (2016) Listening to the brain with photoacoustics. IEEE J. Selected Topics in Quantum Electronics. 22 (3)

6. Ning B, Sun N, Cao R, Chen R, Kirk Shung K, Hossack JA, Lee JM, Zhou Q, Hu S (2015) Ultrasound-aided Multi-parametric Photoacoustic Microscopy of the Mouse Brain. Sci Rep 5:18775.

7. Cao R, Li J, Ning B, Sun N, Wang T, Zuo Z, Hu S (2017) Functional and oxygen-metabolic photoacoustic microscopy of the awake mouse brain. Neuroimage 150:77-87.

8. Cao R, Li J, Zhang C, Zuo Z, Hu S (2019) Photoacoustic microscopy of obesity-induced cerebrovascular alterations. Neuroimage 188:369-379.

9. Sciortino VM, Tran A, Sun N, Cao R, Sun T, Sun YY, Yan P, Zhong F, Zhou Y, Kuan CY, Lee JM, Hu S (2021) Longitudinal cortex-wide monitoring of cerebral hemodynamics and oxygen metabolism in awake mice using multi-parametric photoacoustic microscopy. JCBFM, 271678X211034096. doi: 10.1177/0271678X211034096.

10. Liu P, Chalak LF, Lu H (2014) Non-invasive assessment of neonatal brain oxygen metabolism: A review of newly available techniques. Early Hum Dev 90:695-701.

11. Durduran T, Zhou C, Buckley EM, Kim MN, Yu G, Choe R, Gaynor JW, Spray TL, Durning SM, Mason SE, Montenegro LM, Nicolson SC, Zimmerman RA, Putt ME, Wang J, Greenberg JH, Detre JA, Yodh AG, Licht DJ (2010) Optical measurement of cerebral hemodynamics and oxygen metabolism in neonates with congenital heart defects. J Biomed Opt 15:037004.

12. Dehaes M, Aggarwal A, Lin PY, Rosa Fortuno C, Fenoglio A, Roche-Labarbe N, Soul JS, Franceschini MA, Grant PE (2014) Cerebral oxygen metabolism in neonatal hypoxic ischemic encephalopathy during and after therapeutic hypothermia. J Cereb Blood Flow Metab 34:87-94.

13. Jain V, Buckley EM, Licht DJ, Lynch JM, Schwab PJ, Naim MY, Lavin NA, Nicolson SC, Montenegro LM, Yodh AG, Wehrli FW (2014) Cerebral oxygen metabolism in neonates with congenital heart disease quantified by MRI and optics. J Cereb Blood Flow Metab 34:380-388.

14. Ferradal SL, Yuki K, Vyas R, Ha CG, Yi F, Stopp C, Wypij D, Cheng HH, Newburger JW, 
Kaza AK, Franceschini MA, Kussman BD, Grant PE (2017) Non-invasive assessment of cerebral blood flow and oxygen metabolism in neonate during hypothermic cardiopulmonary bypass: feasibility and clinical implications. Sci Rep 7:44117.

15. De Carli A, Andresen B, Giovannella M, Durduran T, Contini D, Spinelli L, Weigel UM, Passera S, Pesenti N, Mosca F, Torricelli A, Fumagalli M, Greisen G (2019) Cerebral oxygenation and blood flow in term infants during postnatal transition: BabyLux project. Arch Dis Child Fetal Neonatal Ed 104:F648-F653.

16. Rolfe DF, Brown GC (1997) Cellular energy utilization and molecular origin of standard metabolic rate in mammals. Physiol Rev 77:731-758.

17. Lin W, Powers WJ (2018) Oxygen metabolism in acute ischemic stroke. J Cereb Blood Flow Metab 38:1481-1499.

18. Fox PT, Raichle ME, Mintun MA, Dence C (1988) Nonoxidative glucose consumption during focal physiologic neural activity. Science 241:462-464.

19. Lee JM, Vo KD, An H, Celik A, Lee Y, Hsu CY, Lin W (2003) Magnetic resonance cerebral metabolic rate of oxygen utilization in hyperacute stroke patients. Ann Neurol 53:227-232.

20. Rodgers ZB, Detre JA, Wehrli FW (2016) MRI-based methods for quantification of the cerebral metabolic rate of oxygen. J Cereb Blood Flow Metab 36:1165-1185.

21. Liu P, Huang H, Rollins N, Chalak LF, Jeon T, Halovanic C, Lu H (2014) Quantitative assessment of global cerebral metabolic rate of oxygen (CMRO2) in neonates using MRI. NMR Biomed 27:332-340.

22. Grant PE, Roche-Labarbe N, Surova A, Themelis G, Selb J, Warren EK, Krishnamoorthy KS, Boas DA, Franceschini MA (2009) Increased cerebral blood volume and oxygen consumption in neonatal brain injury. J Cereb Blood Flow Metab 29:1704-1713.

23. Winter JD, Tichauer KM, Gelman N, Thompson RT, Lee TY, St Lawrence K (2009) Changes in cerebral oxygen consumption and high-energy phosphates during early recovery in hypoxic-ischemic piglets: a combined near-infrared and magnetic resonance spectroscopy study. Pediatr Res 65:181-187.

24. Gao YR, Ma Y, Zhang Q, Winder AT, Liang Z, Antinori L, Drew PJ, Zhang N (2017) Time to wake up: Studying neurovascular coupling and brain-wide circuit function in the unanesthetized animal. Neuroimage 153:382-398.

25. Slupe AM, Kirsch JR (2018) Effects of anesthesia on cerebral blood flow, metabolism, and neuroprotection. J Cereb Blood Flow Metab 38:2192-2208.

26. Vestergaard MB, Lindberg U, Aachmann-Andersen NJ, Lisbjerg K, Christensen SJ, Law I, Rasmussen P, Olsen NV, Larsson HBW (2016) Acute hypoxia increases the cerebral metabolic rate - a magnetic resonance imaging study. J Cereb Blood Flow Metab 36:10461058.

27. Tsuji M, Naruse H, Volpe J, Holtzman D (1995) Reduction of cytochrome aa3 measured by near-infrared spectroscopy predicts cerebral energy loss in hypoxic piglets. Pediatr Res 
$37: 253-259$.

28. Yang D, Nemkul N, Shereen A, Jone A, Dunn RS, Lawrence DA, Lindquist D, Kuan CY (2009) Therapeutic administration of plasminogen activator inhibitor-1 prevents hypoxicischemic brain injury in newborns. J Neurosci 29:8669-8674.

29. Kuan CY, Chen HR, Gao N, Kuo YM, Chen CW, Yang D, Kinkaid MM, Hu E, Sun YY (2021) Brain-targeted hypoxia-inducible factor stabilization reduces neonatal hypoxicischemic brain injury. Neurobiol Dis 148:105200. doi: 10.1016/j.nbd.2020.105200.

30. Burnsed J, Skwarzynska D, Wagley PK, Isbell L, Kapur J (2019) Neuronal Circuit Activity during Neonatal Hypoxic-Ischemic Seizures in Mice. Ann Neurol 86:927-938.

31. Caspersen CS, Sosunov A, Utkina-Sosunova I, Ratner VI, Starkov AA, Ten VS (2008) An isolation method for assessment of brain mitochondria function in neonatal mice with hypoxic-ischemic brain injury. Dev Neurosci 30:319-324.

32. Juhaszova M, Zorov DB, Kim SH, Pepe S, Fu Q, Fishbein KW, Ziman BD, Wang S, Ytrehus K, Antos CL, Olson EN, Sollott SJ (2004) Glycogen synthase kinase-3beta mediates convergence of protection signaling to inhibit the mitochondrial permeability transition pore. J Clin Invest 113:1535-1549.

33. Zweier JL, Flaherty JT, Weisfeldt ML (1987) Direct measurement of free radical generation following reperfusion of ischemic myocardium. Proc Natl Acad Sci U S A 84:1404-1407.

34. Benzi RH, Lerch R (1992) Dissociation between contractile function and oxidative metabolism in postischemic myocardium. Attenuation by ruthenium red administered during reperfusion. Circ Res 71:567-576.

35. Granger DN, Kvietys PR (2015) Reperfusion injury and reactive oxygen species: The evolution of a concept. Redox Biol 6:524-551.

36. Chen HR, Zhang-Brotzge X, Morozov YM, Li Y, Wang S, Zhang H, Kuan IS, Fugate EM, Mao H, Sun YY, Rakic P, Lindquist DM, DeGrauw T, Kuan CY (2021) Creatine transporter deficiency impairs stress-adaptation and brain energetics homeostasis. JCI Insight 6:e140173.

37. Erecinska M, Thoresen M, Silver IA (2003) Effects of hypothermia on energy metabolism in Mammalian central nervous system. J Cereb Blood Flow Metab 23:513-530.

38. Bale G, Mitra S, Tachtsidis I (2020) Metabolic brain measurements in the newborn: Advances in optical technologies. Physiol Rep 8:e14548.

39. Blumberg RM, Cady EB, Wigglesworth JS, McKenzie JE, Edwards AD (1997) Relation between delayed impairment of cerebral energy metabolism and infarction following transient focal hypoxia-ischaemia in the developing brain. Exp Brain Res 113:130-137.

40. Thornton C, Jones A, Nair S, Aabdien A, Mallard C, Hagberg H (2018) Mitochondrial dynamics, mitophagy and biogenesis in neonatal hypoxic-ischaemic brain injury. FEBS Lett 592:812-830.

41. Salford LG, Siesjo BK (1974) The influence of arterial hypoxia and unilateral carotid artery 
occlusion upon regional blood flow and metabolism in the rat brain. Acta Physiol Scand 92:130-141.

42. Piilgaard H, Lauritzen M (2009) Persistent increase in oxygen consumption and impaired neurovascular coupling after spreading depression in rat neocortex. J Cereb Blood Flow Metab 29:1517-1527.

43. Khacho M, Tarabay M, Patten D, Khacho P, MacLaurin JG, Guadagno J, Bergeron R, Cregan SP, Harper ME, Park DS, Slack RS (2014) Acidosis overrides oxygen deprivation to maintain mitochondrial function and cell survival. Nat Commun 5:3550.

44. Zhu MY, Zhang DL, Zhou C, Chai Z (2019) Mild Acidosis Protects Neurons during OxygenGlucose Deprivation by Reducing Loss of Mitochondrial Respiration. ACS Chem Neurosci 10:2489-2497.

45. Niatsetskaya ZV, Sosunov SA, Matsiukevich D, Utkina-Sosunova IV, Ratner VI, Starkov AA, Ten VS (2012) The oxygen free radicals originating from mitochondrial complex I contribute to oxidative brain injury following hypoxia-ischemia in neonatal mice. J Neurosci $32: 3235-3244$.

46. Kim M, Stepanova A, Niatsetskaya Z, Sosunov S, Arndt S, Murphy MP, Galkin A, Ten VS (2018) Attenuation of oxidative damage by targeting mitochondrial complex I in neonatal hypoxic-ischemic brain injury. Free Radic Biol Med 124:517-524.

47. Chouchani ET et al. (2014) Ischaemic accumulation of succinate controls reperfusion injury through mitochondrial ROS. Nature 515:431-435.

48. Rossi A, Pizzo P, Filadi R (2019) Calcium, mitochondria and cell metabolism: A functional triangle in bioenergetics. Biochim Biophys Acta Mol Cell Res 1866:1068-1078.

49. Cooper CE, Giulivi C (2007) Nitric oxide regulation of mitochondrial oxygen consumption II: Molecular mechanism and tissue physiology. Am J Physiol Cell Physiol 292:C1993-2003.

50. Paradies G, Paradies V, Ruggiero FM, Petrosillo G (2018) Mitochondrial bioenergetics and cardiolipin alterations in myocardial ischemia-reperfusion injury: implications for pharmacological cardioprotection. Am J Physiol Heart Circ Physiol 315:H1341-H1352.

51. Buckley EM, Patel SD, Miller BF, Franceschini MA, Vannucci SJ (2015) In vivo Monitoring of Cerebral Hemodynamics in the Immature Rat: Effects of Hypoxia-Ischemia and Hypothermia. Dev Neurosci 37:407-416.

52. Hagerdal M, Harp J, Siesjo BK (1975) Effect of hypothermia upon organic phosphates, glycolytic metabolites, citric acid cycle intermediates and associated amino acids in rat cerebral cortex. J Neurochem 24:743-748.

53. Berntman L, Welsh FA, Harp JR (1981) Cerebral protective effect of low-grade hypothermia. Anesthesiology 55:495-498.

54. Chatauret N, Zwingmann C, Rose C, Leibfritz D, Butterworth RF (2003) Effects of hypothermia on brain glucose metabolism in acute liver failure: a H/C-nuclear magnetic resonance study. Gastroenterology 125:815-824. 


\section{Methods:}

PAM system: As shown in Fig. 1a, a nanosecond-pulsed laser (wavelength: $532 \mathrm{~nm}$, repetition rate: up to $30 \mathrm{kHz}$; BX40-2-G, EdgeWave) was used in the PAM system for imaging the neonatal mouse brain. The laser beam firstly passed through an electro-optical modulator (EOM; 350-80, Conoptics) and a half-wave plate (HWP; WPH05M-532, Thorlabs) for precise control of the polarization state of the incident beam. By alteration of the voltage applied to the EOM, the polarization state could be dynamically switched between the vertical direction and the horizontal direction, which allowed a polarizing beam splitter (PBS; PBS121, Thorlabs) to dispatch the laser pulses between two optical paths through either reflection or transmission. In the reflection path, after being partially attenuated by a neutral-density filter (NDF; NDC-50C$2 \mathrm{M}$, Thorlabs), the beam was coupled through a fiber collimator (CFC-11X-A, Thorlabs) into a polarization-maintaining single-mode fiber (PM-SMF; F-SPA, Newport) for stimulated Raman scattering-based wavelength conversion ${ }^{1,2}$. The output of the PM-SMF was collimated by an identical collimator and purified by a bandpass filter (BPF; FB560-10, Thorlabs) to isolate the 558-nm component. Then, the 558-nm Raman beam generated in the reflection path and the 532$\mathrm{nm}$ beam in the transmission path were combined by a dichroic mirror (DBS; FF538-FDi01, Semrock) and coupled into a single-mode fiber (SMF; P1-460B-FC-2, Thorlabs) through a fiber collimator (CFC-11X-A, Thorlabs), before which 5\% of the combined beam was picked off by a beam sampler (BS; BSF10-A, Thorlabs) and monitored by a high-speed photodiode (PD; FDS100, Thorlabs) to compensate for possible fluctuation in the laser energy. The dualwavelength laser beam was then delivered to the scanning head, where two identical doublets (DL; AC127-025-A, Thorlabs) were used to map the fiber output into the tissue to be imaged, and a correction lens (CL; LA1207-A, Thorlabs) was used to compensate for the optical aberration at the air-water interface. A ring-shaped ultrasonic transducer (UT; inner diameter: 2.2 $\mathrm{mm}$; outer diameter: $4.0 \mathrm{~mm}$; center frequency: $35 \mathrm{MHz}$; 6-dB bandwidth: 70\%) was used for confocal alignment of the optical excitation and ultrasonic detection. A customized water tank (WT) was used to immerse the ultrasonic transducer for acoustic coupling. The mouse head was fixed to a customized metal arm-piece through a wearable 3-D printed plastic frame for headrestrained awake-brain imaging (Fig. 1b). A water-floated plastic ball (PB; 03170-1008, Blick Art Materials) was used to allow the mouse to move freely with reduced reaction force. A gas 
inlet and a customized face mask from syringe were used to deliver the inhalation gas (i.e., normoxia or hypoxia), as shown in Fig. 1 b.

Procedures for PAM imaging: Before imaging of the neonatal mouse brain, the animal was first anesthetized with vaporized isoflurane (EZ-SA800, E-Z Systems) for installation of the head-restraint plastic frame. Hair on the mouse scalp was removed by a trimmer (9990-1301, Wahl Clipper), and then the scalp was removed with surgical scissors (MDS10030, Medline Industries) to expose the skull. After the clearance of the blood, debris, and remaining hairs, the gel-based cyanoacrylate glue (234790, Loctite) was applied to all edges of the plastic frame, which was attached to the center of the skull between the Bregma and Lambda. After solidification of the applied glue ( $20 \mathrm{~min})$, the frame-worn animal was carefully moved to the plastic ball and secured to the metal arm-piece with two \#4-40 screws. Throughout the frame installation, the body temperature of the mouse was maintained at $37^{\circ} \mathrm{C}$ using a homeothermic monitoring system (No. 69020, RWD life science).

After the installation of the head-restraint frame, a thin layer $(\sim 1 \mathrm{~mm})$ of ultrasound gel (Aquasonic CLEAR ${ }^{\circledR}$, Parker Laboratories) was applied to the surface of the skull for effective acoustic coupling. Then, the metal arm-piece and the plastic ball were carefully raised to bring the gel in gentle contact with the bottom of the water tank, which was filled with temperaturemaintained deionized water. After fully recovering from the anesthesia, the neonatal mouse was ready for awake-brain imaging by the multi-parametric PAM system, which was controlled by a field-programmable gate array (PCIe-7841R, National Instruments) through a self-developed LabVIEW program. For the imaging field covering both hemispheres between the Bregma and Lambda of the neonatal mouse $\left(5 \times 3 \mathrm{~mm}^{2}\right.$ as shown in Fig. 1c), the acquisition time is $\sim 40$ minutes with step sizes set to 0.1 and $10 \mu \mathrm{m}$ along the $x$ - and $y$-direction, respectively. All procedures were approved by the Institutional Animal Care and Use Committees at the University of Virginia and Washington University in St. Louis.

PAM imaging under normothermia or hypothermia: The temperature of the water tank was controlled by a temperature controller (EW-89802-52, Cole-Parmer), which could also be used to effectively regulate the temperature of the underlying mouse skull. Based on our calibration experiment, the normothermia condition $\left(37^{\circ} \mathrm{C}\right)$ could be achieved with the water temperature set 
to $39^{\circ} \mathrm{C}$; while for the two hypothermia conditions $\left(32^{\circ} \mathrm{C}\right.$ or $\left.29^{\circ} \mathrm{C}\right)$, the water temperature was set to $33^{\circ} \mathrm{C}$ or $29^{\circ} \mathrm{C}$, respectively. Throughout all the experiments, the skull temperature was closely monitored by a thin-film temperature sensor (F3132, Omega) attached to the skull. Note that the PAM measurements were performed one hour after each temperature adjustment to ensure equilibrium under the new temperature setting.

PAM imaging under normoxia or hypoxia: For normoxia, the oxygen concentration in the inhalation gas was 21\% (AI M-T, Praxair). For hypoxia, the medical-grade air was mixed with medical-grade nitrogen gas (NI-H, Praxair) through a gas flowmeter mixer (EW-03218-56, ColeParmer) to achieve a reduced oxygen concentration of $10 \%$, which was confirmed by a clinical anesthesia monitor (Capnomac Ultima, Datex-Ohmeda). Under both conditions, the flow rate of the inhalation gas was set to $1.5 \mathrm{~L} / \mathrm{min}$.

PAM imaging of the Vannucci HI model: In the Vannucci HI study, the first PAM image set was acquired at $37^{\circ} \mathrm{C}$ after the unilateral carotid artery ligation. Then, the second image set was acquired at $37^{\circ} \mathrm{C}$ during the one-hour $\mathrm{HI}$ challenge. Subsequently, three sequential image sets were acquired up to 120 minutes (i.e., 0-40, 40-80, and 80-120 minutes) post-HI, either under normothermia $\left(37^{\circ} \mathrm{C}\right)$ or hyperthermia $\left(32^{\circ} \mathrm{C}\right)$ by regulating the temperature of the water tank.

\section{Quantification of cerebral hemodynamics and oxygen metabolism by PAM: Our PAM} technique enables simultaneous quantification of multiple microvascular parameters, including $\mathrm{C}_{\mathrm{Hb}}, \mathrm{sO}_{2}$, and blood flow by the statistical, spectroscopic, and correlation analyses of the acquired A-line signals, respectively. ${ }^{4}$ With our self-developed MATLAB-based vessel segmentation algorithm, ${ }^{3}$ these hemodynamic parameters could be extracted at the singlemicrovessel level. Then, the cerebral blood flow (CBF), oxygen extraction fraction (OEF), and cerebral metabolic rate of oxygen $\left(\mathrm{CMRO}_{2}\right)$ could be obtained by the following formulas:

$$
\begin{aligned}
& C B F=\pi v d^{2} / 8 \\
& O E F=\left(s_{a} O_{2}-s_{v} O_{2}\right) / s_{a} O_{2} \\
& C M R O_{2}=\xi \times C_{H b} \times s_{a} O_{2} \times O E F \times C B F
\end{aligned}
$$


where $d$ is the vascular diameter, $v$ is the peak flow speed along the vascular axis, $s_{a} O_{2}$ and $\mathrm{S}_{v} \mathrm{O}_{2}$ are the $\mathrm{SO}_{2}$ of the feeding arteries and draining veins, respectively, ${ }^{5}$ and $\xi$ is the oxygen binding capacity of hemoglobin $\left(0.014 \mathrm{~L} \mathrm{O}_{2}\right.$ per gram hemoglobin).

Neonatal cerebral HI and hypothermia treatment: The Vannucci model of neonatal HI with and without hypothermia treatment was performed in 10-day-old (P10) C57BL/6 mice as described $^{7,8,9}$. Briefly, P10 pups of both genders anesthetized with $2 \%$ isoflurane were subjected to ligation of the right common carotid artery. After recovery period for one hour, pups were exposed to $10 \% \mathrm{O}_{2}$ for $40 \mathrm{~min}$ in hypoxic chambers at $37^{\circ} \mathrm{C}$. The pups were recovered to normoxia $\left(20.9 \% \mathrm{O}_{2}\right)$ condition, and then randomly divided into normothermia and hypothermia groups with the chambers submerged in a $37^{\circ} \mathrm{C}$ or $32^{\circ} \mathrm{C}$ water bath, separately for a total fourhour treatment. The body temperature of pups was monitored at $37^{\circ} \mathrm{C}$ or $32^{\circ} \mathrm{C}$ using a rectal probe (BAT-12 microprobe; Physitemp) during the treatment.

The measurement of brain infarction: Detection of brain infarction was performed by a triphenyl tetrazolium chloride (TTC, Sigma-Aldrich) staining at $24 \mathrm{~h}$ after HI surgery as previously described ${ }^{7,8}$. The fresh brains were collected after cold-PBS transcardial perfusion. The whole brain (Fig. 4h) or $1 \mathrm{~mm}$-thick brain sections (Fig. 4i) were incubated with 2\% TTC solution, and the TTC-unstained volume $\left(\mathrm{mm}^{3}\right)$ in all sections were quantified using the NIH ImageJ software.

HR-MAS NMR study: The ex vivo NMR experiments and analysis of mice brain tissues were performed as previously reported ${ }^{9}$. Briefly, a $1.5 \mathrm{~mm}$ punch $(\sim 10 \mathrm{mg})$ was taken from snapfrozen brain tissue and loaded into a sample rotor ( $4 \mathrm{~mm} \mathrm{ZrO}_{2}$, Bruker Instruments), with $4 \mu \mathrm{L}$ of deuterium oxide containing $100 \mathrm{mM}$ sodium trimethylsilylpropionate-d4 (TSP, Sigma-Aldrich) added to obtain a frequency-lock signal and serve as an internal standard for chemical shift. HRMAS NMR experiments were then carried out on a Bruker AVANCE 400 WB NMR spectrometer with a dedicated $4 \mathrm{~mm}$ HR-MAS probe. Spinning rates of samples were set to 2500 $\mathrm{kHz}( \pm 2 \mathrm{~Hz})$ at $4^{\circ} \mathrm{C}$. A T2-weighted, water-suppressed Carr-Purcell-Meiboom-Gill pulse sequence was used to acquire the data. The ${ }^{1} \mathrm{H}-\mathrm{NMR}$ spectra were recorded using key parameters as follows: repetition time of 2.0 seconds, spectral width of $4.8 \mathrm{kHz}, 32 \mathrm{~K}$ data points, and 256 
transients. The presence and concentrations of selected metabolites in brain tissue samples were determined based on their chemical shifts and corresponding integrals using Bruker's ERETIC reference method, with $10 \mathrm{mM}$ TSP as the external standard.

ATP detection: The brain ATP level was measured through an ATP Assay Kit according to the manufacturer's instructions (Abcam, Catalog No. ab83355) ${ }^{10}$. Briefly, mouse brains were harvested, washed with $1 \mathrm{X}$ PBS, and then resuspended in $100 \mu \mathrm{L}$ of ATP assay buffer. Cells were homogenized and then centrifuged in $4{ }^{\circ} \mathrm{C}$ at $12,000 \mathrm{~g}$ to remove the insoluble material. The supernatants were collected and incubated with the ATP probe. Absorbance was detected at $580 \mathrm{~nm}$ using a microplate reader (SpectraMax ${ }^{\circledR}$ M3 Microplate Reader; Molecular Devices).

Assessment of isolated brain mitochondrial function: Mitochondria were isolated from the brain tissues using Percoll density gradient centrifugation as previously described ${ }^{11,12}$. Mitochondrial respiration was measured by a Clark-type electrode (Oxytherm; Hansatech). Briefly, $0.05 \mathrm{mg}$ of Mitochondria protein were added into $0.5 \mathrm{ml}$ respiration buffer consist of 200 $\mathrm{mM}$ sucrose, $25 \mathrm{mM} \mathrm{KCl}, 2 \mathrm{mM} \mathrm{K}_{2} \mathrm{HPO}_{4}, 5 \mathrm{mM}$ HEPES, pH 7.2, $5 \mathrm{mM} \mathrm{MgCl}$, $0.2 \mathrm{mg} / \mathrm{ml}$ of BSA, $30 \mu \mathrm{M}$ Ap5A $\left[P^{1}, P^{5}\right.$-di(adenosine 5')-pentaphosphate], $10 \mathrm{mM}$ glutamate, and $5 \mathrm{mM}$ malate or $5 \mathrm{mM}$ succinate and $5 \mathrm{mM}$ glutamate at $32^{\circ} \mathrm{C}$. To initiate State 3 phosphorylating respiration, $100 \mathrm{nmol}$ of ADP was added to the mitochondrial suspension. The rates of $\mathrm{O}_{2}$ consumption were presented in nmol O2/mg mitochondrial protein/min. The respiratory control ratio was calculated as the ratio of the State 3 respiration rate versus the State 4 resting respiration rate recorded after the phosphorylation of ADP has been finished. $35 \mathrm{nM}$ 2'- 4' Dinitro-phenol (DNP) was used to initiate uncoupled respiration ${ }^{13}$.

The rate of $\mathrm{H}_{2} \mathrm{O}_{2}$ emission from isolated mitochondria was measured using a fluorescence assay by the fluorescence spectrophotometer F-7000 (Hitachi High Technologies America, Inc), which set at $555 \mathrm{~nm}$ excitation and $581 \mathrm{~nm}$ emission as previous study ${ }^{14}$. Briefly, $0.05 \mathrm{mg}$ mitochondria were added in $1 \mathrm{ml}$ of respiration buffer and supplemented with $5 \mathrm{mM}$ succinate, $10 \mu \mathrm{M}$ Amplex Ultrared (Invitrogen, Catalog No. A22180), and 4 U/ml horse radish peroxidase (HRP). After recording the fluorescence for $400 \mathrm{~s}$, samples were added with $1 \mu \mathrm{M}$ rotenone and after another $200 \mathrm{~s}$ with $1 \mu \mathrm{g} / \mathrm{ml}$ antimycin A. The calibration curve was calibrated by sequential 
additions of known amounts of $\mathrm{H}_{2} \mathrm{O}_{2}$, with the cuvette containing the respiration buffer, Amplex Ultrared, and HRP.

Superoxide was monitored with MitoSOX Red (Invitrogen, Catalog No. M36008). Briefly, $5 \mu \mathrm{M}$ MitoSOX Red was added to the cuvettes and the fluorescence was measured at $510 \mathrm{~nm}$ excitation and $579 \mathrm{~nm}$ emission wavelengths. Time-dependent monitoring of the MitoSOX Redrelated fluorescence was done using a Fluorescence Spectrophotometer F-7000 (Hitachi High Technologies America, Inc) at $25^{\circ} \mathrm{C}$. The increase of the MitoSOX Red-related fluorescence obtained a saturation kinetics increase after the recording of $25 \mathrm{~min}$. Therefore, the initial rates were used for quantification.

For membrane potential analysis, the rhodamine 123 quenching technique was conducted (Sigma). $0.05 \mathrm{mg}$ isolated mitochondria were incubated with $0.3 \mathrm{mM}$ rhodamine 123 and analyzed by Fluorescence Spectrophotometer F-7000 (Hitachi High Technologies America, Inc) using an excitation and emission wavelength of $503 \mathrm{~nm}$ and $527 \mathrm{~nm}$. During the measurements, the reaction buffer containing mitochondria was continuously stirred. Baseline fluorescence was recorded for $300 \mathrm{~s}$ followed by the sequential addition of oxidizable substrates ( $7 \mathrm{mM}$ succinate or $7 \mathrm{mM}$ malate and glutamate) and $50 \mathrm{mM} \mathrm{CCCP.}$

Video-EEG monitoring: Video-electroencephalogram (EEG) monitoring of mouse neonates was performed as described ${ }^{15}$. Briefly, P9 C57/B16 mice had unipolar insulated stainless steel depth electrodes (0.005 inches bare diameter, 0.008 inches coated; A-M Systems, Sequim, WA, USA) stereotactically implanted in the bilateral parietal cortex ( -1.2 dorsoventral [DV], \pm 0.5 mediolateral $[\mathrm{ML}]$, and -1.0 deep [D] mm), bilateral CA1 region of the hippocampus ( $-3.5 \mathrm{DV}$, $\pm 2.0 \mathrm{ML}$, and $-1.75 \mathrm{D} \mathrm{mm}$ ), and a reference electrode in the cerebellum. Following recovery, mice were exposed to HI on p10. A unity gain impedance matching head stage (TLC2274 Quad Low-Noise Rail-to Rail Operational Amplifier; Texas Instruments, Dallas, TX, USA) was used for recordings, which were begun 1 hour prior to carotid ligation and continued through 2 hours after reoxygenation (excluding the brief ligation procedure); pups were then returned to the dam.

Statistical analysis: One-way ANOVA was used to compare the vascular and oxygen-metabolic changes in the normothermia vs. hyperthermia experiment (Fig. 1e) and the normoxia vs. 
hypoxia experiment (Fig. 1g). Two-way ANOVA was used to compare the oxygen-metabolic changes of the contralateral and ipsilateral hemispheres in the Vannucci HI model under normothermic (Fig. 2c) or hyperthermic (Fig. 3c) condition, as well as hemodynamic and oxygen-metabolic changes 24 hours post-HI (Fig. 4d-f). All data were presented in the form of mean \pm standard deviation of the mean. In all statistical analyses, $p<0.05$ was considered significant.

\section{References (for Methods)}

1. Hajireza, P., Forbrich, A. \& Zemp, R. In-Vivo functional optical-resolution photoacoustic microscopy with stimulated Raman scattering fiber-laser source. Biomed Opt Express 5, 539546 (2014).

2. Hajireza, P., Forbrich, A. \& Zemp, R. J. Multifocus optical-resolution photoacoustic microscopy using stimulated Raman scattering and chromatic aberration. Opt. Lett., OL 38, 2711-2713 (2013).

3. Sun, N. et al. In vivo imaging of hemodynamic redistribution and arteriogenesis across microvascular network. Microcirculation 27, e12598 (2020).

4. Ning, B. et al. Ultrasound-aided Multi-parametric Photoacoustic Microscopy of the Mouse Brain. Sci. Rep 5, 18775 (2015).

5. Yao, J. et al. High-speed Label-free Functional Photoacoustic Microscopy of Mouse Brain in Action. Nat Methods 12, 407-410 (2015).

6. Skeldon, A. C. et al. Modelling and Detecting Tumour Oxygenation Levels. PLOS ONE 7 , e38597 (2012).

7. Yang D, Nemkul N, Shereen A, Jone A, Dunn RS, Lawrence DA, Lindquist D, Kuan CY (2009) Therapeutic administration of plasminogen activator inhibitor-1 prevents hypoxicischemic brain injury in newborns. J Neurosci 29:8669-8674.

8. Kuan CY, Chen HR, Gao N, Kuo YM, Chen CW, Yang D, Kinkaid MM, Hu E, Sun YY (2020) Brain-targeted hypoxia-inducible factor stabilization reduces neonatal hypoxicischemic brain injury. Neurobiol Dis 148:105200.

9. Chen HR, Zhang-Brotzge X, Morozov YM, Li Y, Wang S, Zhang H, Kuan IS, Fugate EM, Mao H, Sun YY, Rakic P, Lindquist DM, DeGrauw T, Kuan CY (2021) Creatine transporter deficiency impairs stress-adaptation and brain energetics homeostasis. JCI Insight 6:e140173.

10. Li C, Zhng Y, Liu J, Kang R, Klionsky DJ, Tang D (2021) Mitochondrial DNA stress triggers autophagy-dependent ferroptotic death. Autophagy 17:948-960.

11. Caspersen CS, Sosunov A, Utkina-Sosunova I, Ratner VI, Starkov AA, Ten VS (2008) An isolation method for assessment of brain mitochondria function in neonatal mice with 
hypoxic-ischemic brain injury. Dev Neurosci 30:319-324.

12. Ten VS, Yao J, Ratner V, Sosunov S, Fraser DA, Botto M, Sivasankar B, Morgan BP, Silverstein S, Stark R, Polin R, Vannucci SJ, Pinsky D, Starkov AA (2010) Complement component clq mediates mitochondria-driven oxidative stress in neonatal hypoxic-ischemic brain injury. J. Neurosci 30:2077-2087.

13. Niatsetskaya ZV, Sosunov SA, Matsiukevich D, Utkina-Sosunova IV, Ratner VI, Starkov AA, Ten VS (2012) The oxygen free radicals originating from mitochondrial complex I contribute to oxidative brain injury following hypoxia-ischemia in neonatal mice. J Neurosci 32:3235-3244.

14. Starkov AA, Fiskum G (2003) Regulation of brain mitochondrial $\mathrm{H} 2 \mathrm{O} 2$ production by membrane potential and NAD(P)H redox state. J. Neurochem 86: 1101-1107.

15. Burnsed J, Skwarzynska D, Wagley PK, Isbell L, Kapur J (2019) Neuronal Circuit Activity during Neonatal Hypoxic-Ischemic Seizures in Mice. Ann Neurol 86:927-938. 
bioRxiv preprint doi: https://doi.org/10.1101/2021.11.29.470404; this version posted November 30, 2021. The copyright holder for this preprint (which was not certified by peer review) is the author/funder, who has granted bioRxiv a license to display the preprint in perpetuity. It is made Figure 1 available under aCC-BY-NC-ND 4.0 International license.

a

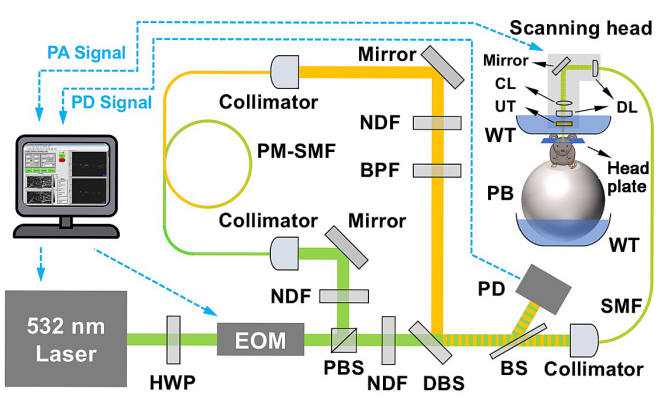

b

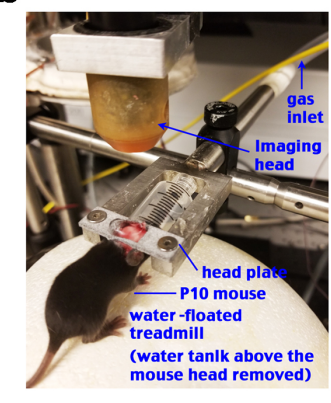

c

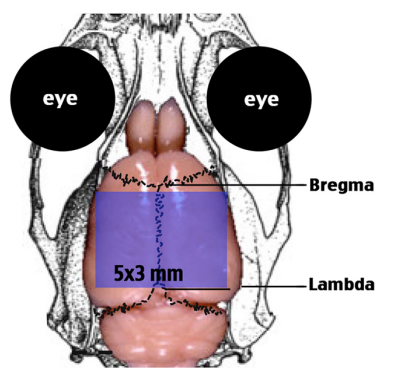

$37^{\circ} \mathrm{C}$ $32^{\circ} \mathrm{C}$ $29^{\circ} \mathrm{C}$
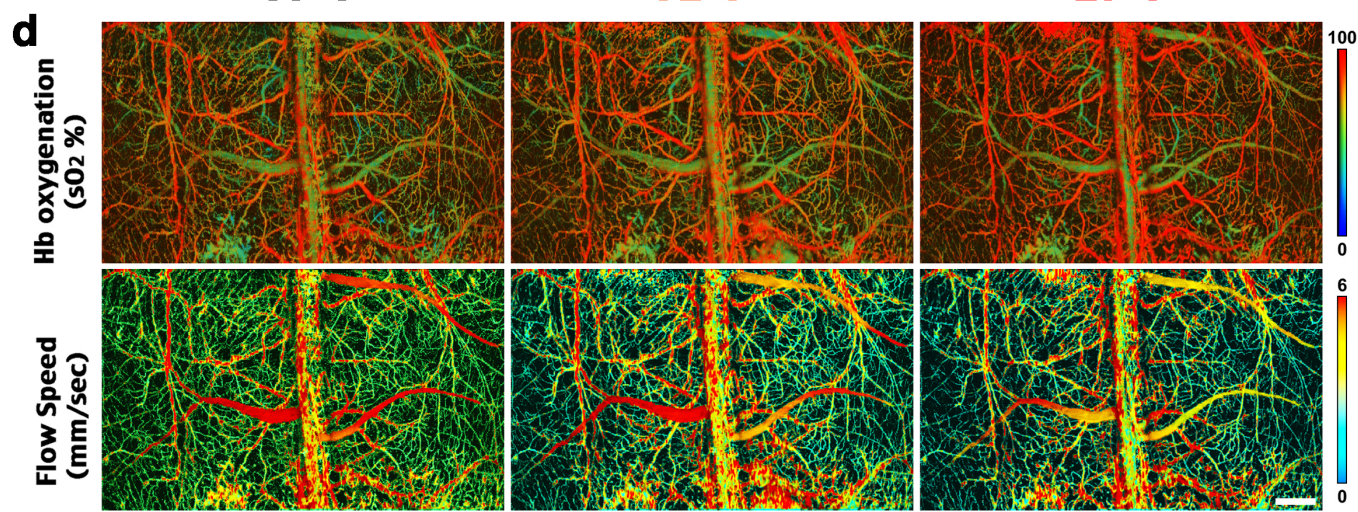

$\mathbf{e}$
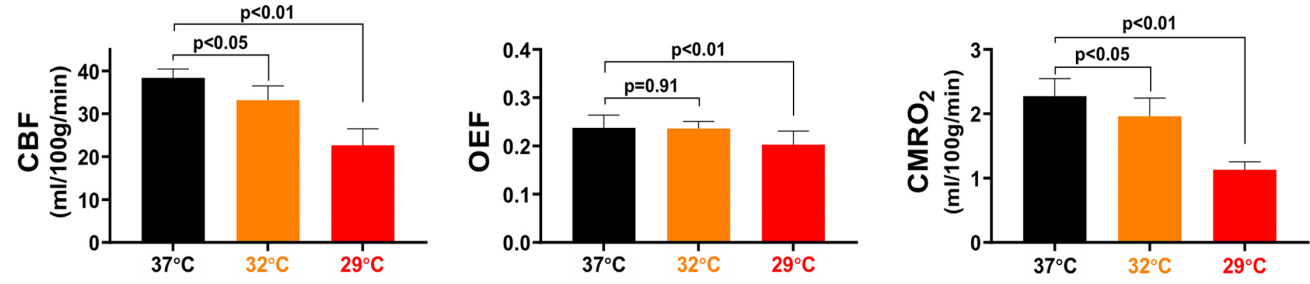

f

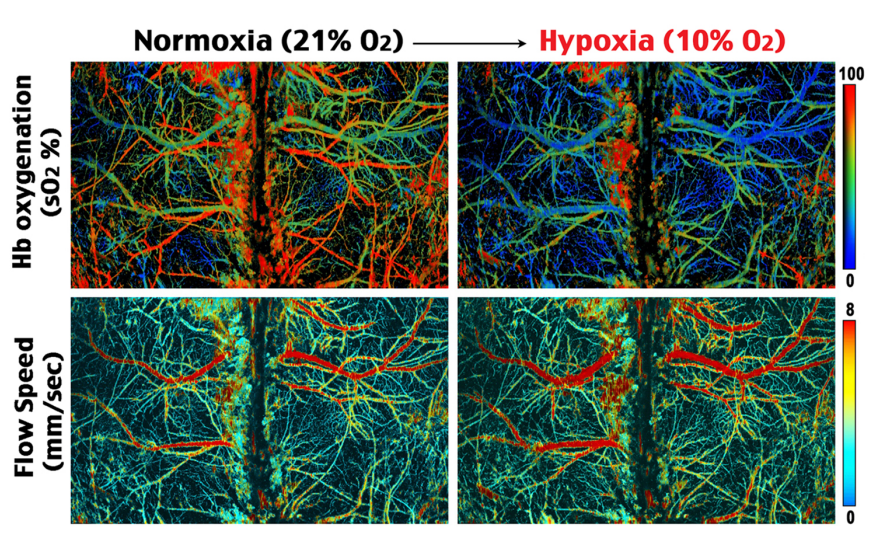

g
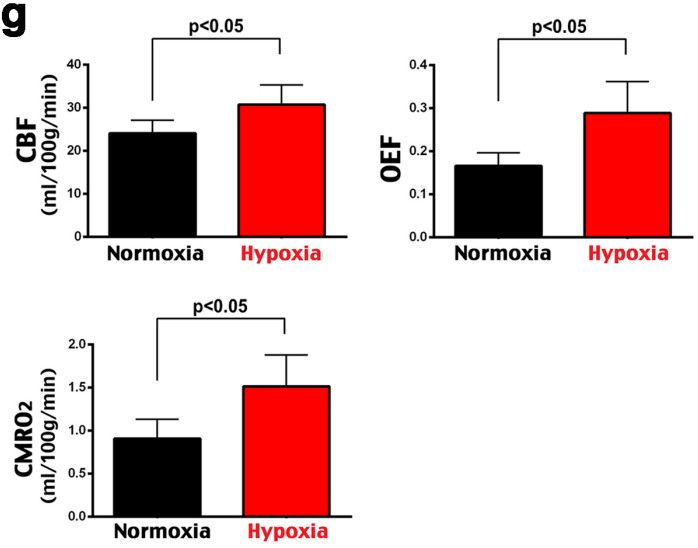
bioRxiv preprint doi: https://doi.org/10.1101/2021.11.29.470404; this version posted November 30, 2021. The copyright holder for this preprint (which was not certified by peer review) is the author/funder, who has granted bioRxiv a license to display the preprint in perpetuity. It is made Figure 2 available under aCC-BY-NC-ND 4.0 International license.

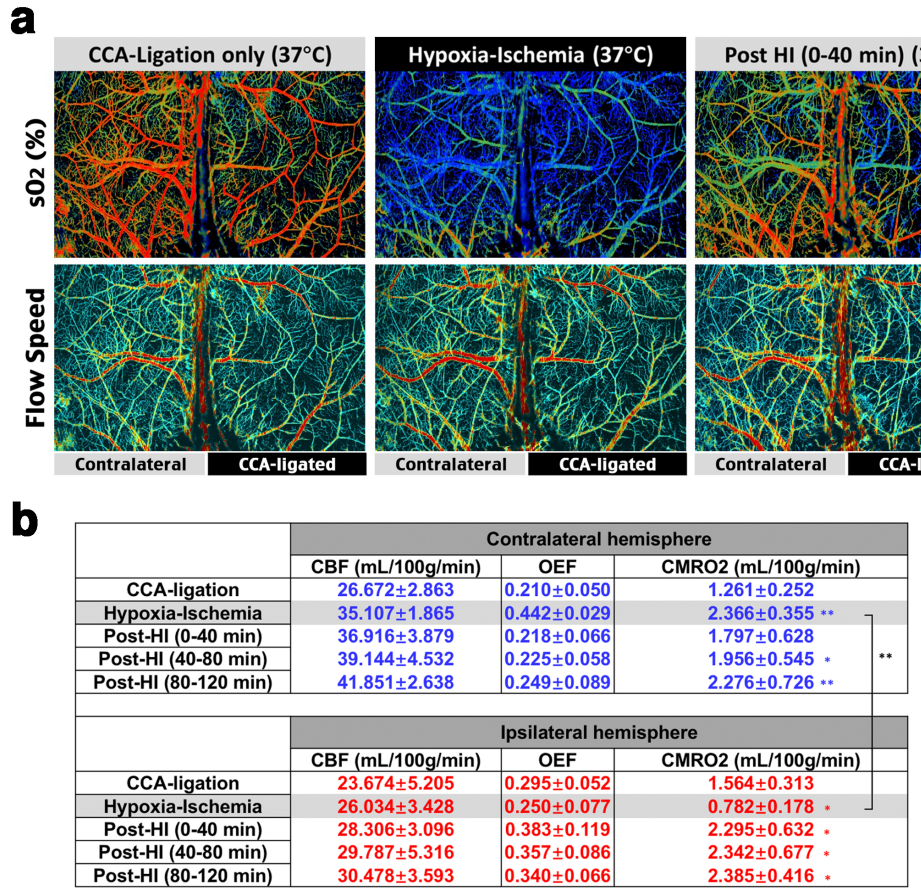

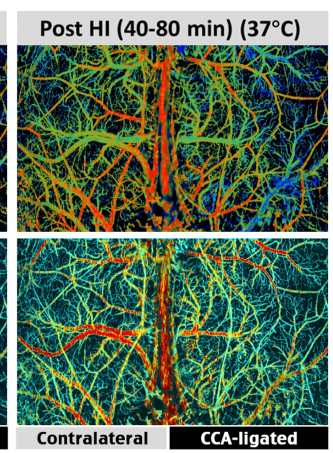

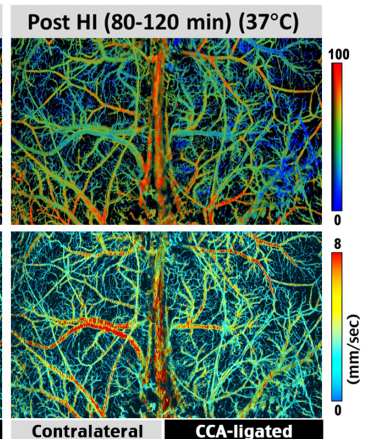

C

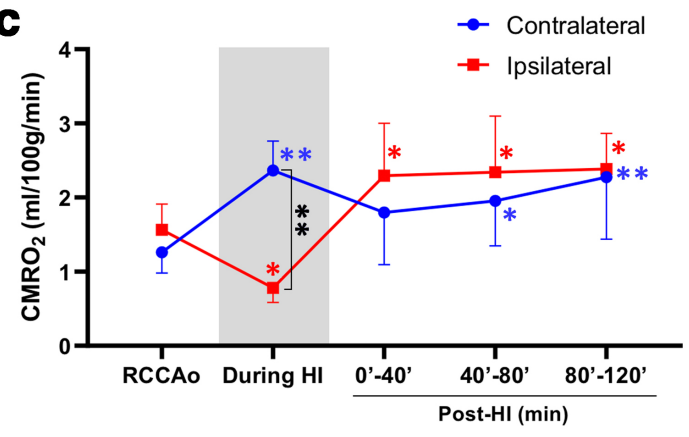

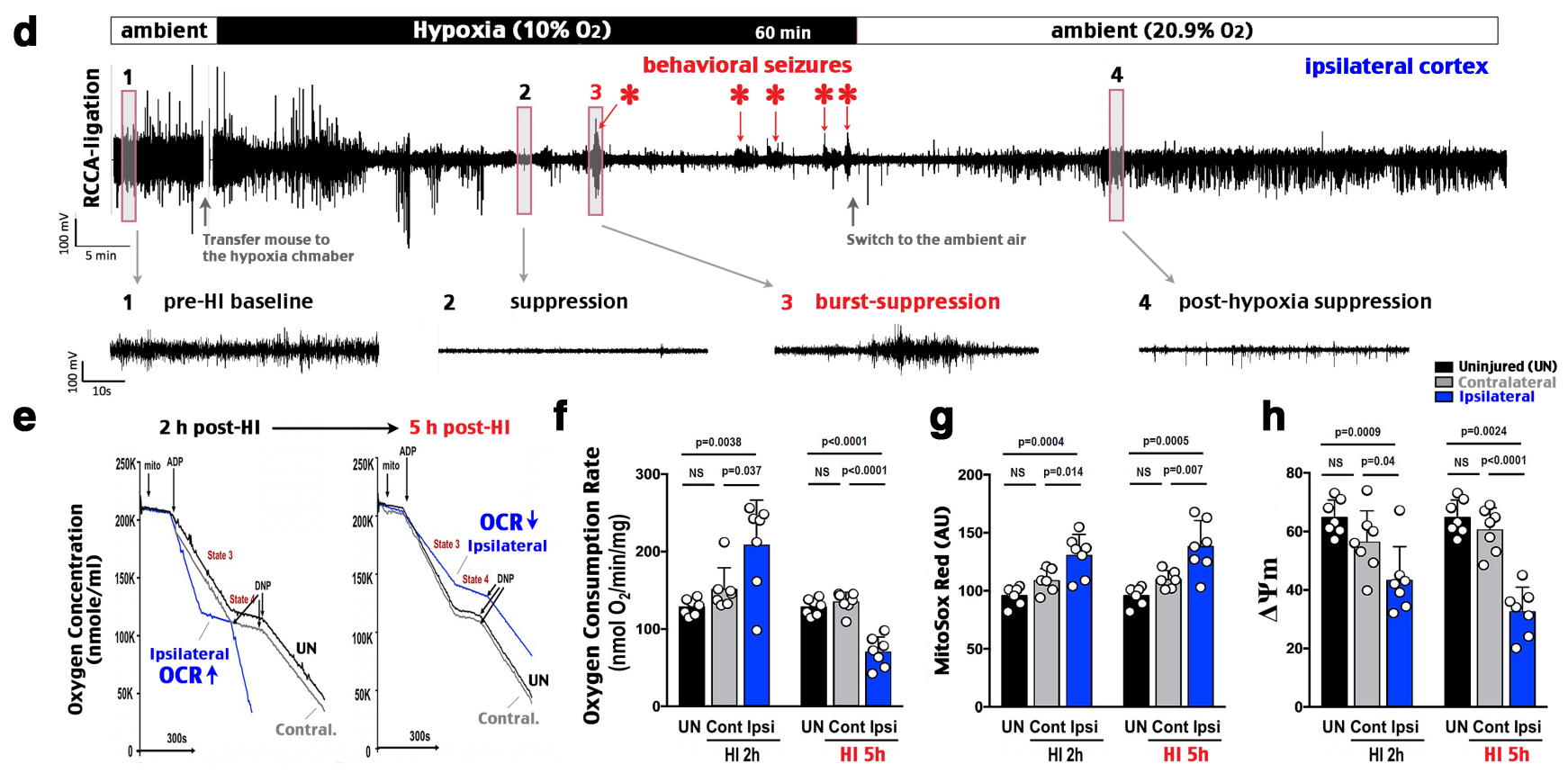


bioRxiv preprint doi: https://doi.org/10.1101/2021.11.29.470404; this version posted November 30, 2021. The copyright holder for this preprint

(which was not certified by peer review) is the author/funder, who has granted bioRxiv a license to display the preprint in perpetuity. It is made Figure 3 available under aCC-BY-NC-ND 4.0 International license.

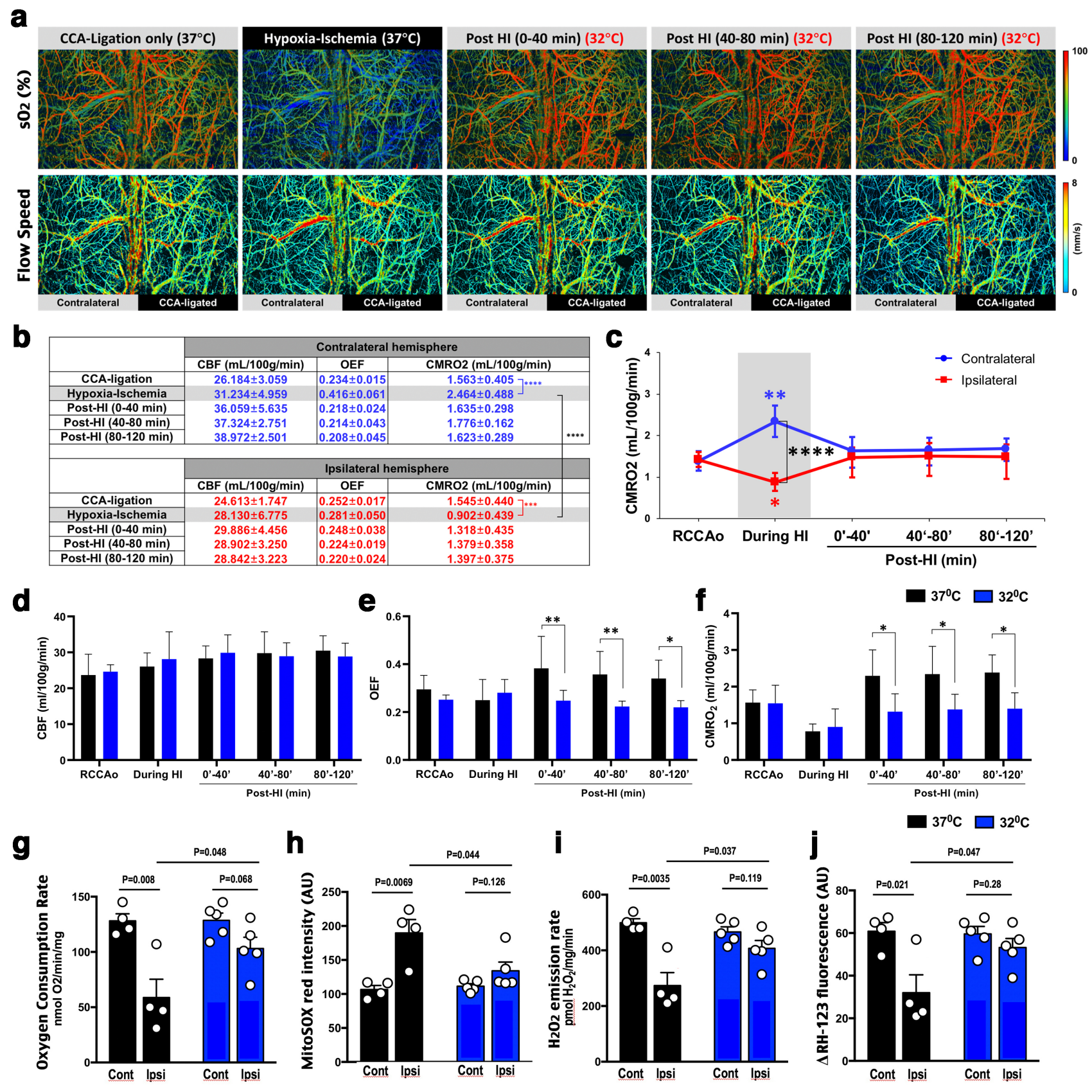


bioRxiv preprint doi: https://doi.org/10.1101/2021.11.29.470404; this version posted November 30, 2021. The copyright holder for this preprint

(which was not certified by peer review) is the author/funder, who has granted bioRxiv a license to display the preprint in perpetuity. It is made Figure 4 available under aCC-BY-NC-ND 4.0 International license.

a

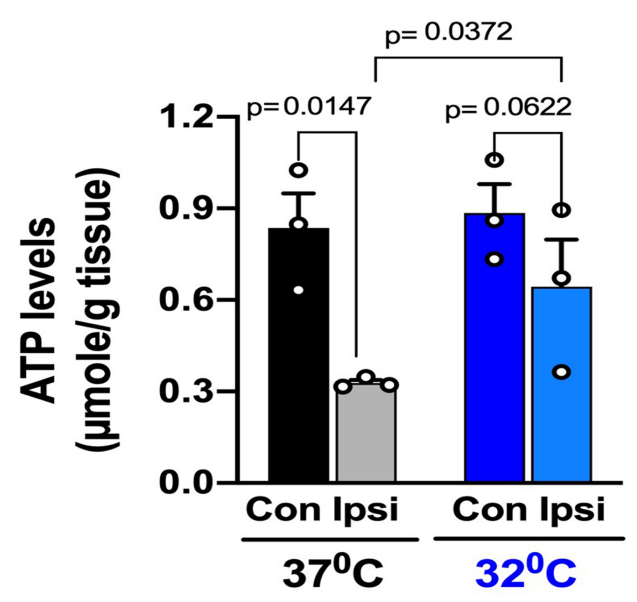

b Normothermia
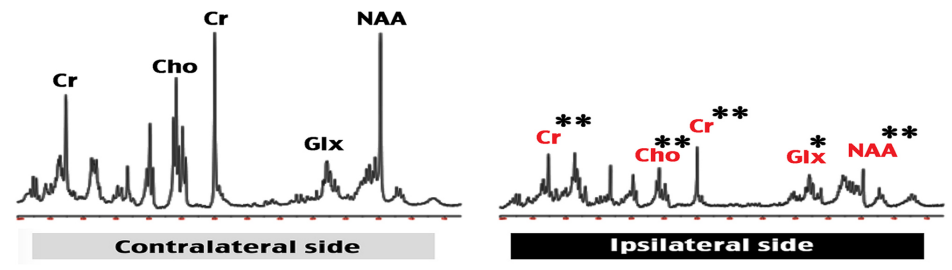

C Hypothermia

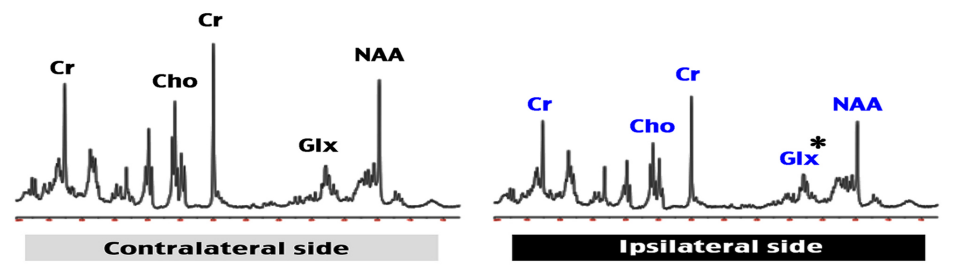

f

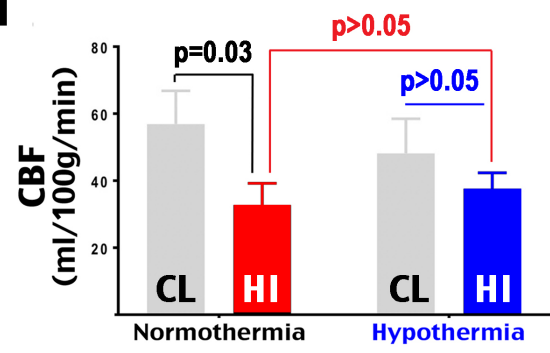

e

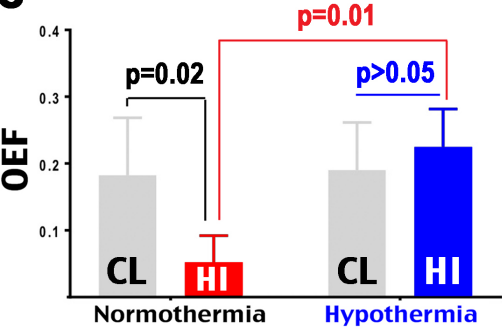

\section{I}

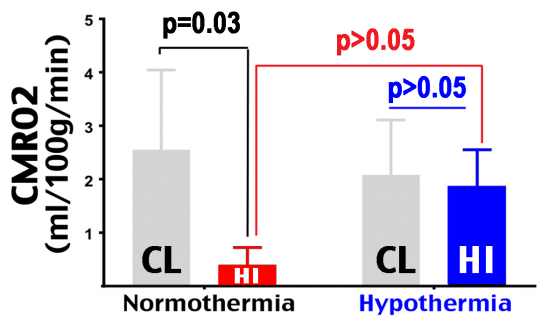

$\mathbf{g}$

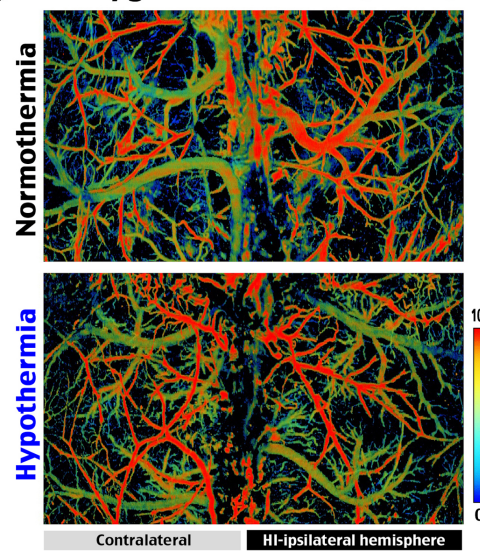

i

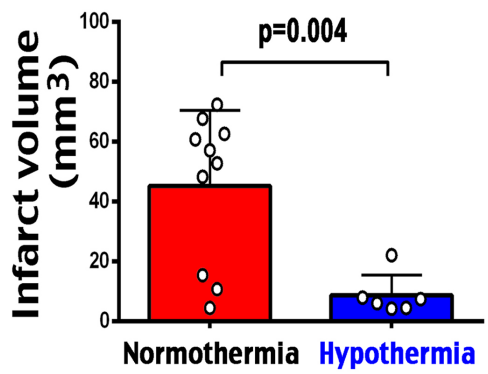

Flow speed $(\mathrm{mm} / \mathrm{s})$
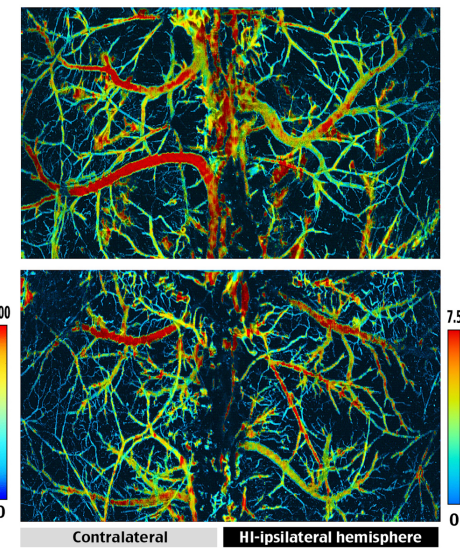

h $\mathrm{CMRO}_{2}(\mathrm{ml} / 100 \mathrm{~g} / \mathrm{min})$
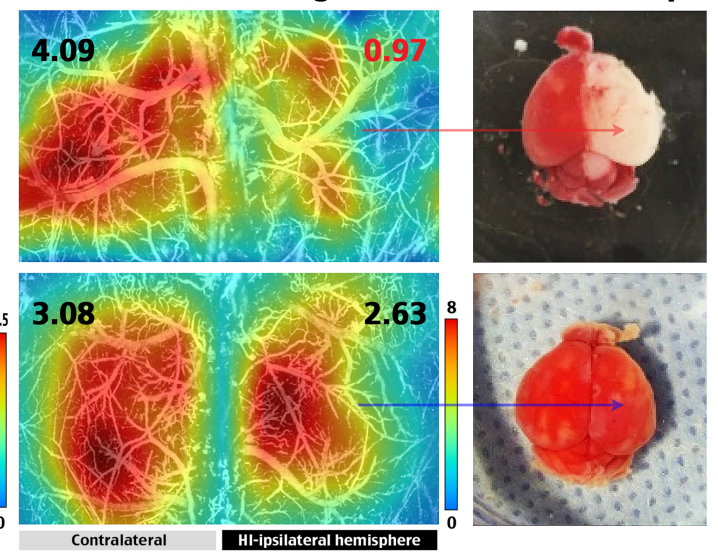

TTC stain (dip)

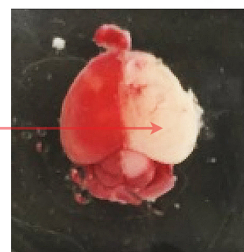

j
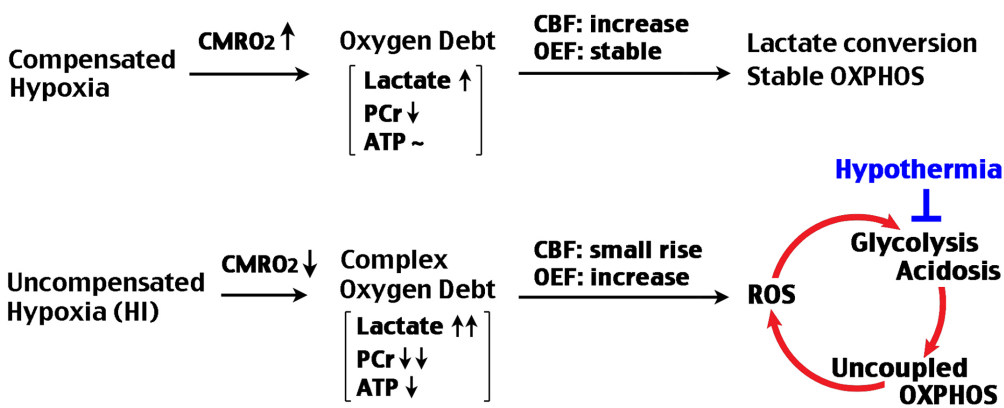
bioRxiv preprint doi: $\mathrm{https}$ //doi.org/10.1101/2021.11.29.470404; this version posted November 30,2021 . The copyright holder for this preprint (which was not certified by peer review) is the author/funder, who has granted bioRxiv a license to display the preprint in perpetuity. It is made available under aCC-BY-NC-ND 4.0 International license.

\section{Supplementary Figure 1:}

Relationship of the water tank and mouse skull temperatures.

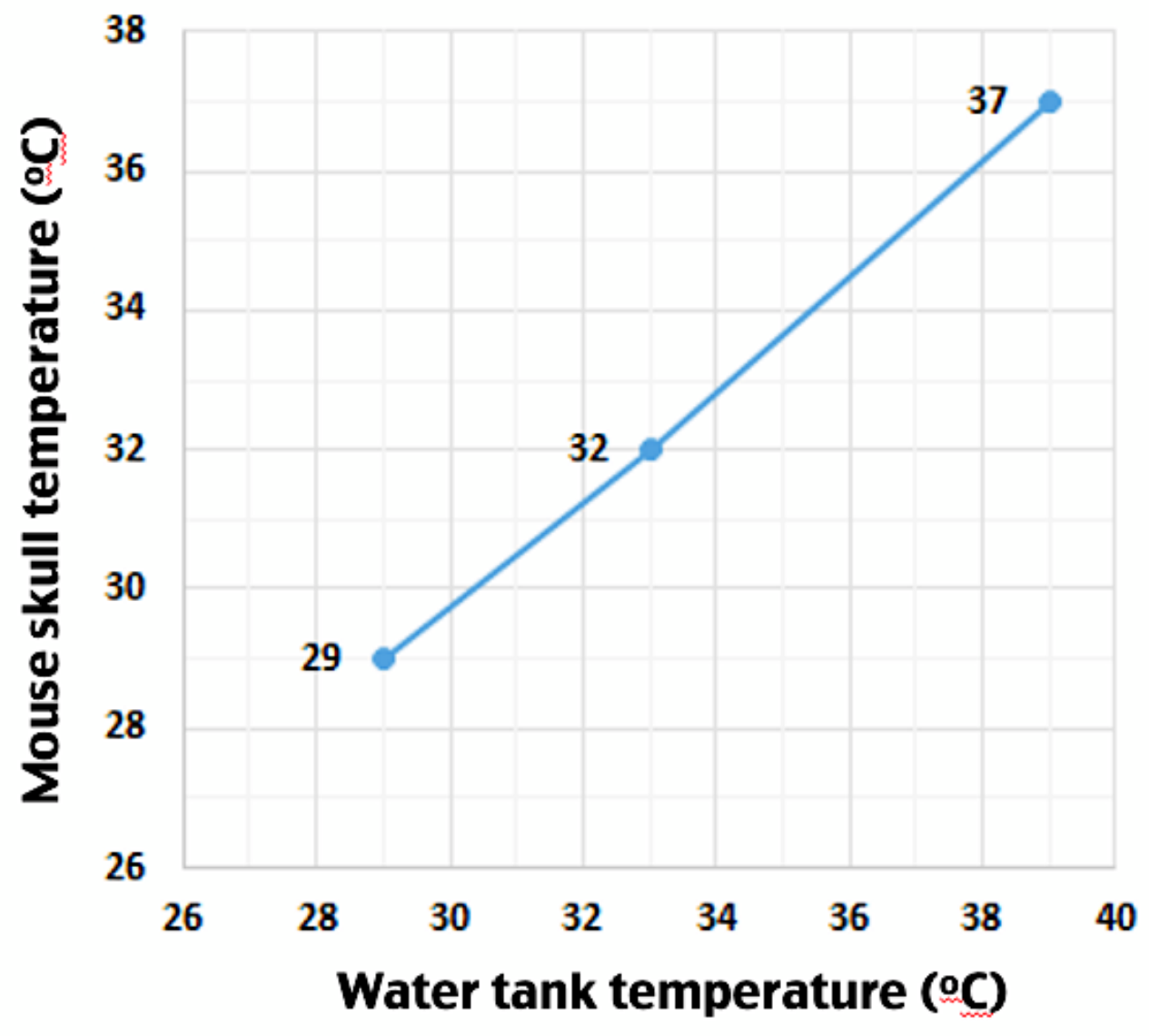




\section{Supplementary Figure 2:}

${ }^{1} \mathrm{H}$ HRMAS MRS analysis of the effects of hypothermia on brain metabolites at $24 \mathrm{~h}$ post-HI.

\begin{tabular}{|l|l|l|l|l|}
\hline Metabolite (AU) & Ipsi (37) & Contra (37) & Ipsi (32) & Contra (32) \\
\hline NAA & $0.87(0.48)^{* *}$ & $1.84(0.26)$ & $1.21(0.33)$ & $1.60(0.09)$ \\
\hline Cr & $0.57(0.35)^{* *}$ & $1.26(0.20)$ & $0.82(0.18)$ & $1.06(0.16)$ \\
\hline Cho & $1.63(0.86)^{* *}$ & $4.81(1.41)$ & $2.70(0.27)^{+}$ & $3.74(1.10)$ \\
\hline GLX & $1.29(0.49)^{*}$ & $1.90(0.13)$ & $1.48(0.24)$ & $1.63(0.12)^{*}$ \\
\hline NAA/GLX & $0.52(0.32)^{*}$ & $1.54(0.40)$ & $0.70(0.13)$ & $1.09(0.13)$ \\
\hline
\end{tabular}

Data presented as mean (standard deviation). ${ }^{*} \mathrm{P}<0.05 ; * * \mathrm{p}<0.01$ relative to contralateral side at $\mathrm{T}=37 \mathrm{C}$. ${ }^{+} \mathrm{P}<0.05$ relative to ipsilateral side at $\mathrm{T}=37 \mathrm{C}$. Two-way ANOVA with side and temperature as the independent factors showed significant differences between the ipsi- and contralateral sides.

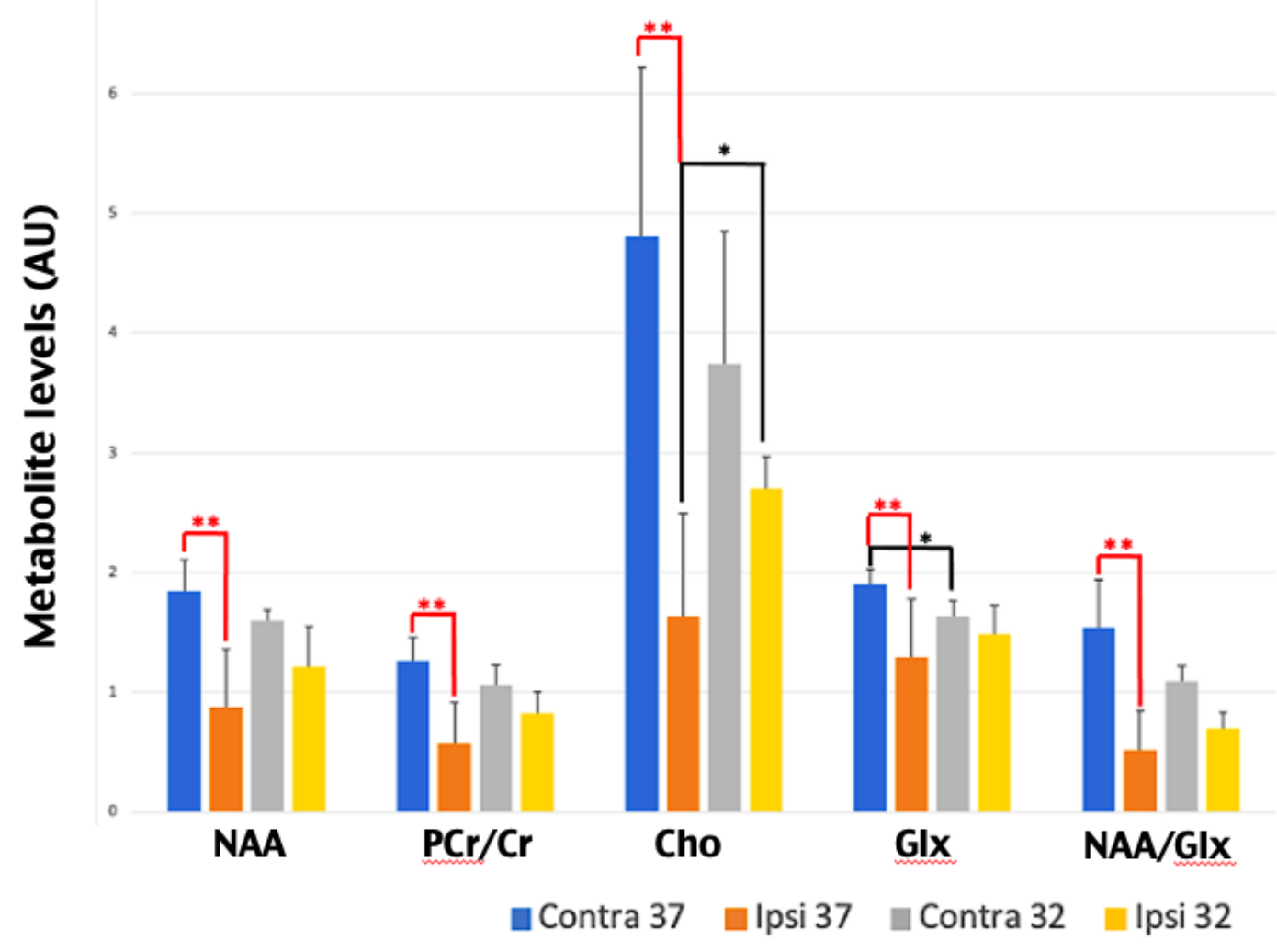


bioRxiv preprint doi: https://doi.org/10.1101/2021.11.29.470404 this version posted November 30,2021 . The copyright holder for this preprint (which was not certified by peer review) is the author/funder, who has granted bioRxiv a license to display the preprint in perpetuity. It is made available under aCC-BY-NC-ND 4.0 International license.

\section{Supplementary Figure 3:}

Potential mechanisms that contribute to uncoupling of OXPHOS after $\mathrm{HI}$ and the effects of therapeutic hypothermia.

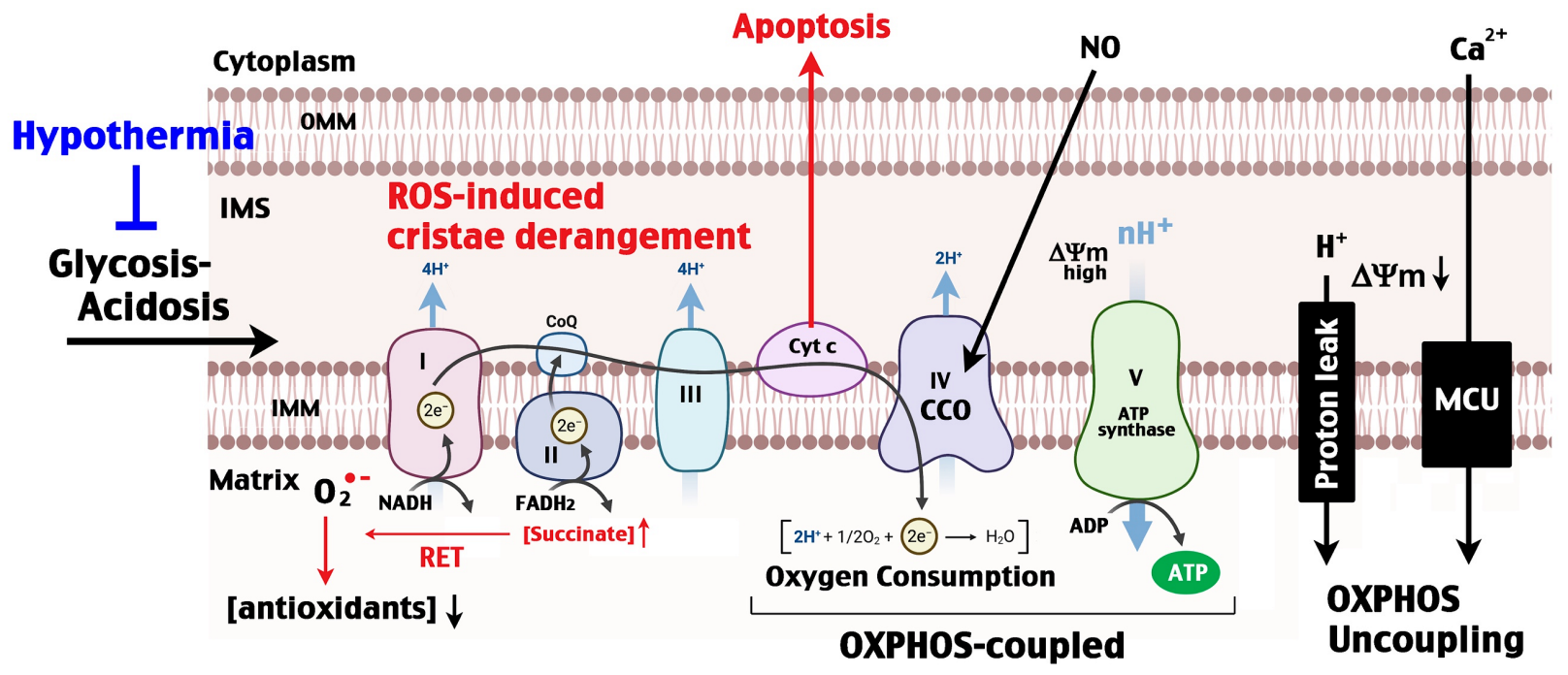

